\title{
Petrografia e geoquímica das rochas metamáficas intercaladas em gnaisses do Arco Magmático de Goiás na região de Indiara (GO)
} Petrography and geochemistry of metamafic rocks intercalated in gneisses from Goiás Magmatic Arc, region of Indiara (GO)

\author{
Guillermo Rafael Beltran Navarro', Regiane Andrade Fumes², Antenor Zanardo', \\ Marcos Aurélio Farias de Oliveira ${ }^{1}$, George Luiz Luvizotto ${ }^{1}$ \\ 'Departamento de Petrologia e Metalogenia, Instituto de Geociências e Ciências Exatas, Universidade Estadual Paulista \\ "Júlio de Mesquita Filho" - UNESP, Avenida 24-A 1.515 - Bela Vista, CEP 13506-900, Rio Claro, SP, BR (navarro@rc.unesp.br, \\ azanardo@rc.unesp.br, maurelio@rc.unesp.br, georgell@rc.unesp.br \\ Graduação em Geologia, Instituto de Geociências e Ciências Exatas, Universidade Estadual Paulista "Júlio de Mesquita Filho" - \\ UNESP, Rio Claro, SP, BR (regianefumes@gmail.com.br)
}

Recebido em 24 de julho de 2014; aceito em 09 de janeiro de 2015

\begin{abstract}
Resumo
Na região de Indiara (GO), ocorrem dezenas de lentes de rochas metamáficas de dimensões variadas (métricas a quilométricas), intercaladas em gnaisses do Arco Magmático de Goiás e orientadas segundo a direção da foliação principal (Sn). Essas lentes são constituídas por anfibolitos (anfibólio xistos e anfibolitos), apresentam composições químicas de basaltos subalcalinos a basaltos andesíticos e possuem afinidade toleítica subalcalina. A distribuição dos elementos maiores, traços e terras raras (ETR) sugere que essas rochas derivam de uma fonte com assinatura geoquímica semelhante. As rochas analisadas apresentam enriquecimento em elementos litófilos de raio iônico grande ( $\mathrm{Cs}, \mathrm{Rb}, \mathrm{Ba}, \mathrm{K}$, Th e U) em relação a elementos de alto campo de força ( $\mathrm{Nb}$, Ta, Zr, Hf e Y) e em relação a ETR, Sr, P e Ti, mostrando fracas a médias anomalias negativas de $\mathrm{Nb}$, Ta e $\mathrm{P}$ e sugerindo que essas rochas foram geradas em ambientes de arcos magmáticos.
\end{abstract}

Palavras-chave: Faixa Brasília; Província Tocantins; Goiás.

Abstract

In Indiara region (GO), dozens of metamafic rocks lenses of various dimensions (metric to kilometric) occur, intercalated in gneisses of the Goiás Magmatic Arc and oriented according to the direction of the main foliation (Sn). These lenses consist of amphibolite (amphibole schists and amphibolites), have chemical compositions of sub-alkaline basalts to andesitic basalts and sub-alkaline tholeiitic affinity. The distribution of major and trace elements, as well as rare earth elements (REE), suggests that these rocks are derived from a source with similar geochemical signature. The analyzed rocks are enriched in large ion litophile elements $(\mathrm{Cs}, \mathrm{Rb}, \mathrm{Ba}, \mathrm{K}$, Th and $\mathrm{U}$ ) in relation to elements of high field strength $(\mathrm{Nb}, \mathrm{Ta}, \mathrm{Zr}, \mathrm{Hf}$ and $\mathrm{Y}$ ) and in relation to REE, Sr, $\mathrm{P}$ and Ti, showing weak to medium negative anomalies of $\mathrm{Nb}$, Ta and $\mathrm{P}$ and suggesting that these rocks were generated in a magmatic arc environment.

Keywords: Brasília Belt; Tocantins Province; Goiás. 


\section{INTRODUÇÃO}

A área de estudo situa-se na porção central da Província Tocantins (Almeida, 1967; Almeida et al., 1981), próximo ao contato entre as rochas da Sequência Metavulcanossedimentar Anicuns-Itaberaí (Barbosa, 1987) e os terrenos gnáissicos associados ao Arco Magmático de Goiás (Pimentel e Fuck, 1991, 1992; Pimentel et al., 2000a) (Figura 1).

Trabalhos regionais elaborados por Barbosa et al. (1966, 1970), Oliveira e Bittar (1971), Schobbenhaus et al. (1975a, 1975b), Marini et al. (1978, 1984a, 1984b), Danni e Fuck (1981), Ianhez et al. (1983), Valente (1986), Lacerda Filho et al. (1999), entre outros, relacionaram a extensa área de rochas gnáissicas que ocorrem na região ao embasamento da Faixa Brasília, de idade arqueana e/ou paleoproterozoica.

Lacerda Filho et al. (1999) agruparam as rochas da área de estudo como pertencentes à Unidade GranitosGnaisses Indiferenciados, pertencente ao Complexo Granito Gnáissico, de idade arqueana. Essas rochas, segundo os autores, distribuem-se amplamente, como faixas mais ou menos contínuas, na região centro-oeste do Estado de Goiás. Nas proximidades da área de estudo, as rochas do Complexo Granito Gnáissico fazem contato tectônico com as rochas da Sequência Metavulcanossedimentar AnicunsItaberai e com granitos neoproterozoicos sin- a tardi-tectônicos tipo Rio Piracanjuba, a E-NE da área de estudo. A Unidade Granitos-Gnaisses Indiferenciados corresponde a granitoides homogêneos e/ou gnaissificados, caracterizados como rochas do embasamento arqueano, representadas por ortognaisses graníticos, tonalíticos e granodioríticos, às vezes milonitizados e contendo restitos de rochas básicas a ultrabásicas, com ocorrências frequentes de diques e stocks máfico-ultramáficos. Os gnaisses da Unidade GranitoGnaisses Indiferenciados são geralmente ricos em biotita e hornblenda e estão representados predominantemente por tonalitos, biotita granitos e um conjunto de gnaisses porfiríticos de granulação média, com foliação e bandamento, às vezes exibindo espessas zonas de cisalhamento dúcteis com veios pegmatíticos (Lacerda Filho e Oliveira, 1994; Lacerda Filho et al., 1999).

Segundo Lacerda Filho et al. (1999), a Sequência Metavulcanossedimentar Anicuns-Itaberai (Figura 1) (anteriormente relacionada ao Grupo Araxá por Oliveira e Bittar, 1971; Araújo et al., 1980; Ianhez et al., 1983, entre outros, e ao Greenstone belt de Santa Rita por Barbosa, 1987) é composta por uma sequência de rochas paleoproterozoicas, constituída por metavulcânicas básicas a intermediárias (anfibolito, anfibólio xisto, epidoto anfibolito, clorita xisto e quartzo-clorita xisto com intercalações centimétricas a métricas de metachert piritoso), rochas químico-exalativas/mistas (metachert, metachert piritoso, formações ferríferas que ocorrem como lentes em quartzo-clorita xisto, quartzo-clorita-sericita-plagioclásio xisto, muscovita xisto e cianita-muscovita xisto de provável origem tufácea) e rochas metassedimentares (biotita-clorita-muscovita xisto, biotita calcixisto, biotita xisto grafitoso, granada-muscovita-biotita xisto, quartzito, quartzito ferruginoso, cianita-muscovita-sericita-cloritoide xisto e sericita-clorita-quartzo xisto). Ocorrem ainda nessa unidade lentes de calcários (metacalcário dolomítico com lentes de calcário silicoso) e mármores (mármores magnesianos e dolomíticos com lentes decimétricas de metacalcário silicoso), bem como intercalações de rochas ultrabásicas (serpentinitos, talco xistos, talco-tremolita xistos, tremolititos e actinolita xistos), milonitizadas e metamorfizadas na fácies xisto verde baixo a anfibolito.

Dados isotópicos e geocronológicos obtidos nas regiões NW e SW do Estado de Goiás demostraram que as extensas áreas de rochas gnáissicas e sequências metavulcanossedimentares, anteriormente relacionadas ao embasamento de idade arqueana/paleoproterozoica, correspondem a terrenos juvenis neoproterozoicos e são incluídas no Arco Magmático de Goiás (Pimentel e Fuck, 1991, 1992; Pimentel et al., 2000a, 2000b, 2004; Dardenne, 2000; Fuck, 1994; Fuck et al., 1994, 2005; Viana et al., 1995; Rodrigues et al., 1999; Laux et al., 2001, 2003, 2005, 2010; Navarro et al., 2004, 2013a; Moreira et al., 2008).

O Arco Magmático de Goiás é constituído por terrenos de ortognaisses (gnaisse Arenópolis, Matrinxã, Sancrerlândia, Firminópolis, Turviânia, Mara Rosa, Palminópolis e granitoide Choupana), originados de rochas plutônicas geradas em ambiente de arco de ilhas, granitos miloníticos (granitos Macacos, Serra do Tatu e Mina de Posse), que ocorrem associados às sequências metavulcanossedimentares (sequências Arenópolis, Iporá, Amorinópolis, Jaupaci, Bom Jardim de Goiás, Anicuns-Itaberaí, Mara Rosa e Santa Terezinha) constituídas por rochas metavulcânicas (metabasaltos e metatufos intermediários), metassedimentos (pelitos a psamíticos), metassedimentos químicos (metacherts e formações ferríferas) e rochas metaultramáficas.

Ao longo do Arco Magmático de Goiás, ocorrem corpos intrusivos de composição granítica (os corpos mais bem estudados são os granitos Serra Negra, Serra do Irã, Caiapó, Iporá, Israelândia, Serra do Impertinente, Fazenda Nova e Novo Brasil) e básica-ultrabásica (os corpos mais bem estudados são os complexos Americano do Brasil, Anicuns-Santa Bárbara e diorito Córrego do Lajeado) com características tardi- a pós-orogênicas.

Os dados geocronológicos e isotópicos disponíveis sugerem que o Arco Magmático de Goiás é resultado de um sistema de arcos de ilhas intraoceânico, caracterizados por rochas plutônicas (cálcico-alcalinas) e vulcânicas (de composição dacítica a andesito basáltica). Tais arcos foram formados entre $\sim 900 \mathrm{e} \sim 600 \mathrm{Ma}$, sendo resultado de dois eventos de acresção crustal: um entre $\sim 900$ e $\sim 800$ Ma e o outro entre $\sim 670$ a $\sim 600 \mathrm{Ma}$ (Pimentel et al., 2004; Laux et al., 2005). 


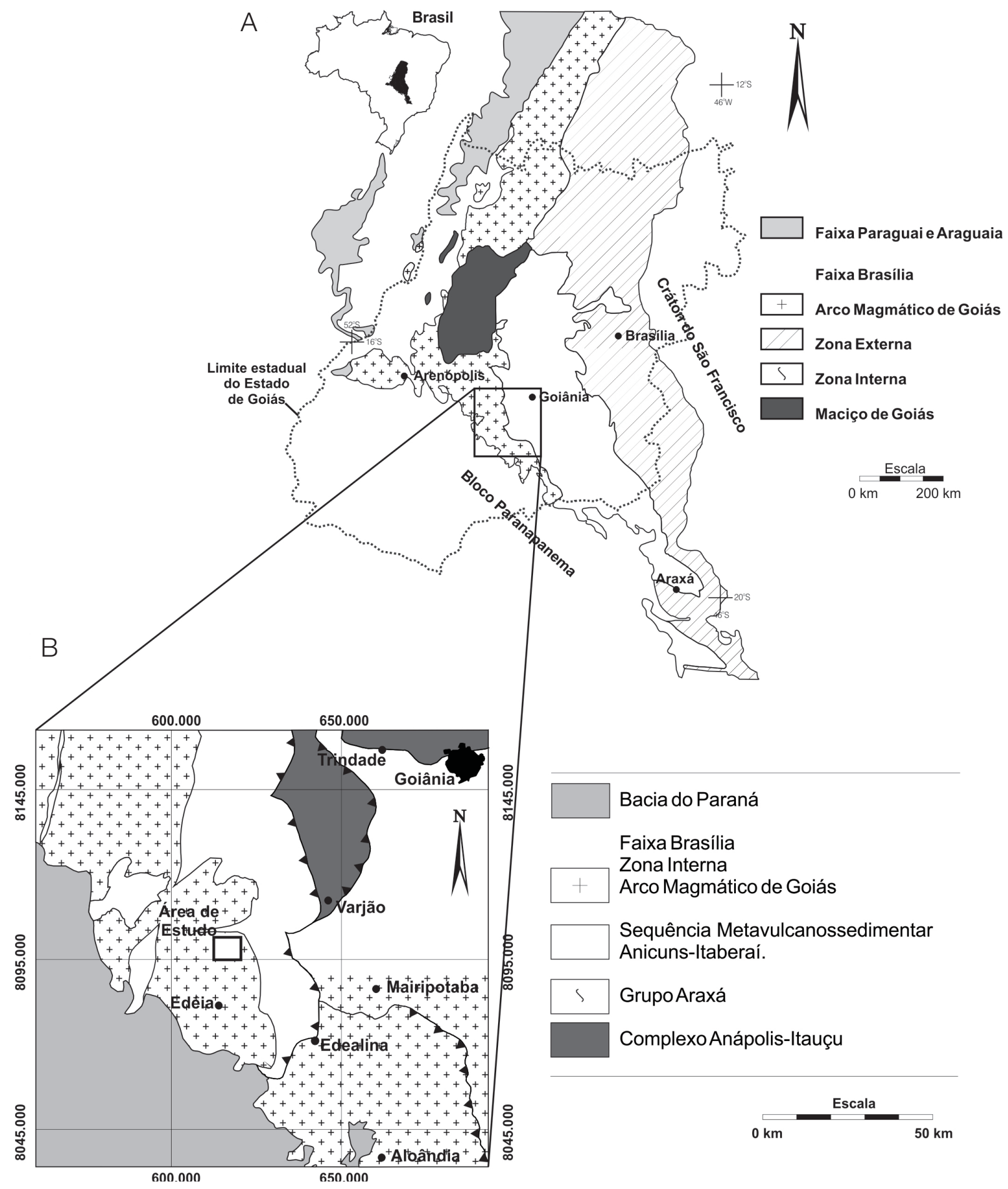

Figura 1. (A) Mapa esquemático da Província Tocantins (modificado de Fuck, 1990); (B) mapa geológico regional simplificado de parte da Província Tocantins na porção S de Goiás, mostrando a localização da área de estudo (modificado de Moreira et al., 2008). 


\section{GEOLOGIA LOCAL}

A estruturação da região corresponde, de modo geral, ao traçado tectono-estratigráfico proposto por outros autores (Oliveira e Bittar, 1971; Araújo et al., 1980; Ianhez et al., 1983; Lacerda Filho et al., 1999; Simões, 2005; Moreira et al., 2008) para a área de estudo e é constituída por um conjunto de rochas, onde os litotipos dominantes são gnaisses, relacionados ao Arco Magmático de Goiás (Figura 2), ao qual se associam rochas metamáficas (anfibolio xistos e anfibolitos) e metassedimentares (mármores, granada-biotita xistos e biotita xistos).

Os principais litotipos encontrados na área de estudo são muscovita gnaisse com biotita e biotita ortognaisse com muscovita, comumente quartzosos, leucocráticos a mesocráticos. Localmente, ocorrem granada-biotita-muscovita xisto porfiroblásticos intercalados em muscovita gnaisse. Os gnaisses são fracamente bandados (apresentam bandamento milimétrico descontínuo) de cor cinza a esbranquiçada ou branco acinzentada, frequentemente com coloração avermelhada devido a alteração e aspecto xistoso, feição também realçada pela alteração intempérica. As rochas descritas anteriormente apresentam foliação bem desenvolvida, localmente dobrada (dobras suaves métricas) - raramente apresentando dobras intrafoliares, assimétricas e apertadas -, e normalmente constituem tectonitos S-L a L-S. A textura dessas rochas é granoblástica, com domínios lepidoblásticos, ou transicional entre granoblásticos a lepidoblásticos. A granulação das rochas é média a fina, localmente com porções porfiroclásticas.

As porções porfiroclásticas são constituídas principalmente por biotita gnaisse porfiroclástico com ou sem muscovita, sendo que os porfiroclastos são de feldspato, chegam a atingir $4 \mathrm{~cm}$ de comprimento, possuem formas sub-retangulares a ovaladas e estão orientados segundo a foliação principal. Porções pegmatíticas ocorrem localmente, intercaladas paralelamente ao bandamento composicional dos gnaisses, podendo, em alguns casos, atingir alguns metros de espessura. Esses pegmatitos são constituídos por muscovita de granulação grossa a pegmatoide, feldspato potássico (microclínio) que pode atingir até $5 \mathrm{~cm}$ de comprimento e quartzo branco a transparente. Alguns desses pegmatitos contêm cristais de turmalina (schorlita), podendo, em alguns casos, atingir prismas de até $6 \mathrm{~cm}$ de comprimento.

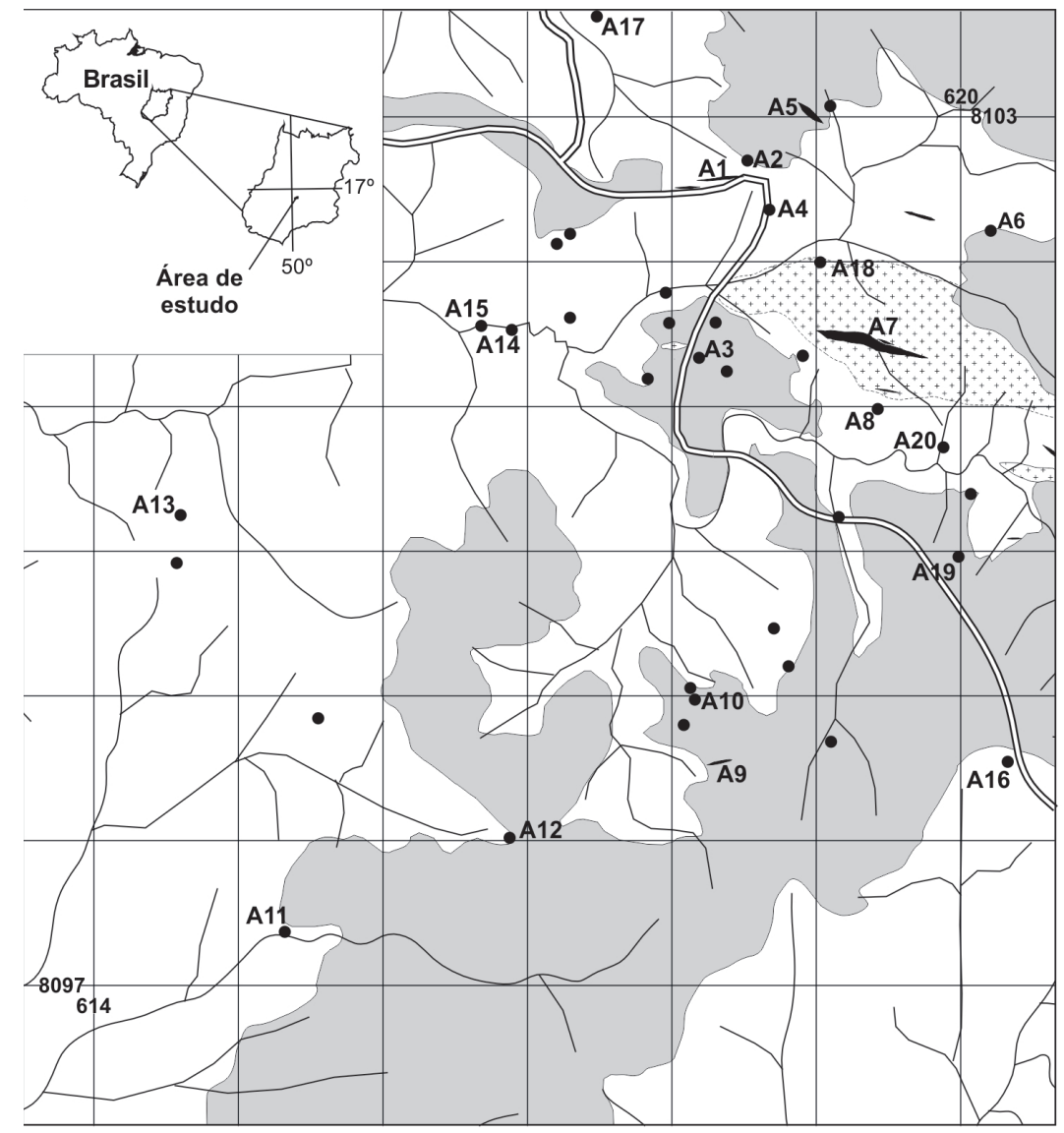

Depósitos terciários/quaternários Arco Magmático de Goiás

Rochas metamáficas

Biotita gnaisse porfiroclástico Muscovita gnaisses, biotita gnaisses

Lentes de metamáficas não cartografáveis - na escala de trabalho Drenagens $\approx$ Estradas

Figura 2. Mapa geológico esquemático da área de estudo, mostrando a localização das amostras analisadas. 
Na região E da área de estudo, aflora um biotita ortognaisse porfiroclástico, de cor branca acinzentada a cinza esbranquiçada, granulação média a grossa e matriz granoblástica. Apresenta manchas e/ou agregados lenticulares lepidoblásticos constituídos por biotita e, subordinadamente, por muscovita, dispostos paralelamente à foliação. Localmente, mostra porções mais finas de cor branca acinzentada a cinza esbranquiçada, constituídas por muscovita-biotita gnaisse de granulação fina a média.

Quimicamente, os gnaisses da região possuem composição cálcico-alcalina e peraluminosa (Figuras 3A e 3B), sendo classificados como granitos (Figura 3C). A composição, com base no conteúdo de feldspato normativo, varia de trondhjemito a granito, predominando os termos de composição granítica (Figura 3D). Mostram enriquecimentos em elementos terras raras leves (ETRL) e elementos litófilos de raio iônico grande (LILE) em relação a elementos de alto campo de força (HFSE), anomalias negativas de $\mathrm{Nb}$, Ta, P e Ti e baixos conteúdos de Y e Yb (Figuras 3E e 3F). Exibem composições químicas semelhantes às rochas plutônicas geradas em arcos magmáticos com características sin-colisionais (Figuras 3G e 3H).

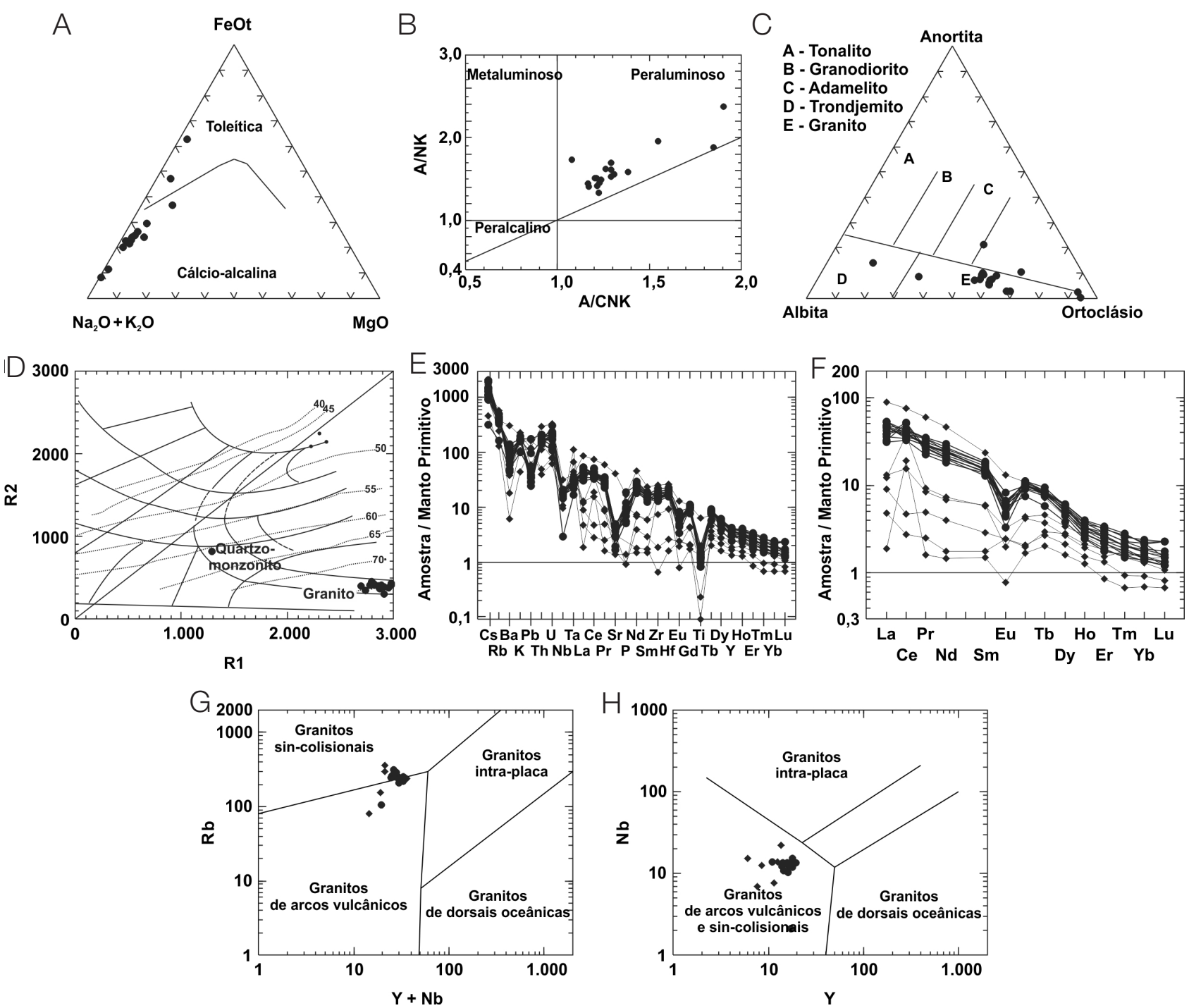

Figura 3. Características geoquímicas de gnaisses da área de estudo (Navarro et al., 2013b). (A) Diagrama AFM (Irvine e Baragar, 1971, $\mathrm{A}=\mathrm{Na}_{2} \mathrm{O}+\mathrm{K}_{2} \mathrm{O} ; \mathrm{F}=\mathrm{FeO}_{\mathrm{T}}, \mathrm{M}=\mathrm{MgO}$ ); (B) gráfico de classificação do índice de Shand (Maniar e Picolli, 1989) - A/NK: $\mathrm{Al}_{2} \mathrm{O}_{3} / \mathrm{Na}_{2} \mathrm{O}+\mathrm{K}_{2} \mathrm{O} ; \mathrm{A} / \mathrm{CNK}: \mathrm{Al}_{2} \mathrm{O}_{3} / \mathrm{CaO}+\mathrm{Na}_{2} \mathrm{O}+\mathrm{K}_{2} \mathrm{O}$; (C) gráfico de classificação baseado no teor de feldspato normativo; (D) diagrama de classificação para rochas plutônicas Ri x R2 (De La Roche et al., 1980); (E e F) spiderdiagram de elementos menores, traços e elementos terras raras e diagrama de distribuição dos elementos terras raras, ambos normalizados pelo Manto Primitivo (Taylor e MacLennan, 1985); (G e H) diagramas discriminantes de ambientes tectônicos (Pearce et al., 1984). 
Granada-biotita-muscovita xisto e/ou granada-biotitamuscovita gnaisse porfiroblástico ocorrem como camadas e/ou lentes de espessuras métricas. Apresentam textura lepidoblástica com domínios granoblásticos, coloração cinza, granulação fina a média e estrutura xistosa dobrada. Os profiroblastos são de granada idiomórfica a hipidiomórfica, de dimensões médias de $0,5 \mathrm{~mm}$.

Veios de quartzo de cor branca ou transparentes, de granulação média a grossa, com muscovita e às vezes com turmalina (schorlita) - e mais raramente com cristais centimétricos de cianita - ocorrem na forma de blocos em meio às áreas de pastagens e nas drenagens.

Em certas porções de relevo suave, utilizadas para pastagens e agricultura, entre solos de espessuras métricas, esbranquiçados a creme ou vermelho amarronzado a marrom avermelhado, ocorrem raros afloramentos de lateritas alteradas e de gnaisses.

As rochas metamáficas ocorrem intercaladas nos gnaisses e são identificadas como anfibólio xisto e mais raramente como anfibolito. Apresentam dimensões variadas, formando lentes métricas (podem chegar a ter algumas dezenas de metros de espessura e largura). Possuem textura nematoblástica a granoblástica, granulação fina a média e coloração verde escura.

As paragêneses e associações minerais presentes nas rochas da região, relacionadas ao metamorfismo, são típicas da fácies anfibolito. Nos gnaisses, as associações minerais relacionadas ao metamorfismo são marcadas pela presença de plagioclásio (oligoclásio/andesina) + feldspato potássico (microclínio) + biotita, ambas as associações com quartzo e muscovita associados, e localmente com granada e rutilo + titanita associados. A paragênese cianita + granada + feldspato $\mathrm{K}$ (microclínio) + plagioclásio (oligoclásio) + biotita + muscovita + rutilo foi observada em apenas uma amostra. Essas associações indicam metamorfismo em fácies anfibolito (campo de estabilidade da cianita) em regime de pressão compatível ou superior ao barroviano.

Aspectos texturais e estruturais indicam que essas associações foram geradas no estágio inicial do desenvolvimento da foliação principal (Sn) ou mesmo antes (Sn-1).

Retrometamorfismo de fácies xisto verde alto a moderado é observado em algumas amostras. Este é caracterizado pela muscovitização de cianita e plagioclásio, saussuritização de plagioclásio, alteração parcial de biotita e granada para clorita, de rutilo para titanita, titanita para ilmenita etc.

\section{MATERIAIS E MÉTODOS}

Foram selecionadas 35 amostras de rochas metamáficas para estudos petrográficos. A análise consistiu de observação de seções delgadas através de microscopia de luz transmitida, realizada em microscópio monocular de marca Leitz (Wetzlar
SM-Lux Pol), com aumentos de 40, 100, 250 e 630 vezes. Destas, foram selecionadas 20 amostras para estudos litogeoquímicos de elementos maiores, menores, traços e elementos terras raras (ETR). As análises químicas foram realizadas pelo Laboratório Acme (Analytical Laboratories LTD, Vancouver, Canadá). Os elementos maiores $\left(\mathrm{SiO}_{2}\right.$, $\mathrm{TiO}_{2}, \mathrm{Al}_{2} \mathrm{O}_{3}, \mathrm{Fe}_{2} \mathrm{O}_{3} \mathrm{~T}, \mathrm{MnO}, \mathrm{MgO}, \mathrm{CaO}, \mathrm{Na}_{2} \mathrm{O}, \mathrm{K}_{2} \mathrm{O}, \mathrm{P}_{2} \mathrm{O}_{5} \mathrm{e}$ também o $\mathrm{Cr}_{2} \mathrm{O}_{3}$ ) foram analisados por Espectrometria de Emissão Atômica por Plasma Acoplado Indutivamente (ICPOES), após fusão, utilizando-se metaborato/tetraborado de lítio e digestão em ácido nítrico diluído, sendo a perda ao fogo (LOI) determinada pela diferença de peso da amostra antes e depois do aquecimento a $100^{\circ} \mathrm{C}$ por $4 \mathrm{~h}$. Os elementos traços (Ba, Co, Cs, Ga, Hf, Nb, Rb, Sc, Sr, Ta, Th, U, V, $\mathrm{Y}$ e $\mathrm{Zr}$ ) e terras raras ( $\mathrm{La}, \mathrm{Ce}, \mathrm{Pr}, \mathrm{Nd}, \mathrm{Sm}, \mathrm{Eu}, \mathrm{Gd}, \mathrm{Tb}, \mathrm{Dy}$, $\mathrm{Ho}, \mathrm{Er}, \mathrm{Tm}, \mathrm{Yb}$ e Lu) foram analisados no Espectrômetro de Massa em Plasma Indutivamente Acoplado (ICP-MS), após fusão, utilizando-se metaborato/tetraborado de lítio e digestão em ácido nítrico, sendo que, para os metais $\mathrm{Cu}$, $\mathrm{Ni}, \mathrm{Pb}$ e $\mathrm{Zn}$, a digestão foi por água régia. O tratamento dos dados químicos e a construção de diagramas foram realizados com emprego do programa MINPET versão 2.02 (Richard, 1995). Os resultados são mostrados na Tabela 1 e a localização das amostras na Figura 2.

\section{PETROGRAFIA DAS ROCHAS METAMÁFICAS}

As rochas metamáficas possuem granulação fina a média, raramente média a grossa, cor verde escura, textura nematoblástica a decussada, com ou sem domínios granoblásticos (lenticulares, irregulares ou formando trilhas), e estrutura levemente orientada a xistosa. Localmente, apresentam bandamento descontínuo marcado por pequenas lentes quartzo/feldspáticas e domínios nematoblásticos. As rochas metamáficas de granulação média a grossa possuem textura decussada a nematoblástica e domínios granoblásticos que formam "manchas" irregulares, cuja trama sugere resquícios de textura ofítica a subofítica. São constituídos principalmente por hornblenda, plagioclásio e quartzo. Como minerais acessórios e/ou secundários, ocorrem granada, epidoto, biotita, apatita, rutilo, titanita, zircão, allanita e clorita.

A hornblenda ( $60-75 \%)$ é o anfibólio presente nas rochas metamáficas analisadas. Ocorre orientada segundo a foliação em grau variado; em alguns litotipos, apresenta baixo grau de orientação, é xenomórfica a hipidiomórfica. Apresenta pleocroísmo leve a forte com cor amarela acastanhada clara, verde oliva a verde azulada. As dimensões médias variam entre $400-600 \mu \mathrm{m}$. Pode constituir porfiroblastos de até $1,7 \mathrm{~mm}$, às vezes, poiquiloblastos (com inclusões de plagioclásio, quartzo, rutilo, epidoto e opacos).

O plagioclásio (20-35\%) é representado por oligoclásio/ andesina. Ocorre em domínios granoblásticos constituindo 
Tabela 1. Teores de elementos maiores (em \%), elementos traço (em ppm) e elementos terras raras (em ppm) das rochas metamáficas analisadas da região de Indiara (GO).

\begin{tabular}{|c|c|c|c|c|c|c|c|c|c|c|}
\hline Amostra & A1 & $\mathrm{A} 2$ & A3 & A4 & A5 & A6 & A7 & A8 & A9 & A10 \\
\hline $\mathrm{SiO}_{2}$ & 50,02 & 48,42 & 50,15 & 48,5 & 48,69 & 50 & 49,97 & 48,38 & 50,50 & 49,69 \\
\hline $\mathrm{TiO}_{2}$ & 1,31 & 1,81 & 1,6 & 1,5 & 1,39 & 1,48 & 1,36 & 1,14 & 1,07 & 1,35 \\
\hline $\mathrm{Al}_{2} \mathrm{O}_{3}$ & 14,23 & 16,69 & 14,57 & 15,81 & 15,3 & 14,42 & 14,33 & 16,98 & 14,38 & 14,52 \\
\hline $\mathrm{Fe}_{2} \mathrm{O}_{3}$ & 12,07 & 10,24 & 11,1 & 11,39 & 11,4 & 10,79 & 11,98 & 10,8 & 10,87 & 11,99 \\
\hline $\mathrm{MnO}$ & 0,19 & 0,17 & 0,17 & 0,17 & 0,17 & 0,16 & 0,19 & 0,16 & 0,18 & 0,19 \\
\hline $\mathrm{MgO}$ & 7,3 & 8,27 & 7,33 & 8,06 & 8,26 & 7,75 & 7,3 & 8,08 & 7,92 & 7,51 \\
\hline $\mathrm{CaO}$ & 11,06 & 10,12 & 10,96 & 10,69 & 10,74 & 11,38 & 10,87 & 9,95 & 11,08 & 10,77 \\
\hline $\mathrm{Na}_{2} \mathrm{O}$ & 1,92 & 1,86 & 2,33 & 2,1 & 2,29 & 2,29 & 2,16 & 0,98 & 2,29 & 2,35 \\
\hline $\mathrm{K}_{2} \mathrm{O}$ & 0,31 & 0,82 & 0,62 & 0,33 & 0,45 & 0,6 & 0,36 & 0,38 & 0,33 & 0,41 \\
\hline $\mathrm{P}_{2} \mathrm{O}_{5}$ & 0,1 & 0,17 & 0,13 & 0,11 & 0,11 & 0,12 & 0,11 & 0,1 & 0,08 & 0,11 \\
\hline LOI & 1,3 & 1,1 & 0,8 & 1,1 & 0,9 & 0,7 & 1,1 & 2,8 & 1,1 & 0,9 \\
\hline Total & 99,8 & 99,77 & 99,79 & 99,79 & 99,79 & 99,79 & 99,8 & 99,8 & 99,79 & 99,79 \\
\hline Sc & 40 & 32 & 36 & 35 & 36 & 37 & 40 & 36 & 40 & 41 \\
\hline V & 309 & 214 & 243 & 248 & 235 & 224 & 300 & 236 & 263 & 299 \\
\hline $\mathrm{Cr}$ & 116,32 & 294,21 & 218,95 & 335,26 & 335,26 & 260,00 & 102,63 & 403,68 & 123,16 & 102,63 \\
\hline Co & 44,3 & 42,8 & 42,8 & 52 & 44,6 & 39,1 & 44,5 & 36,2 & 41,9 & 46,3 \\
\hline $\mathrm{Ni}$ & 8,1 & 72,6 & 24,9 & 56,3 & 28,4 & 20,9 & 7,9 & 26,9 & 7,6 & 11,1 \\
\hline $\mathrm{Cu}$ & 26,1 & 43,6 & 75,5 & 102,5 & 60,9 & 68,3 & 22,6 & 50,6 & 20,9 & 21,2 \\
\hline Zn & 24 & 17 & 17 & 17 & 14 & 15 & 23 & 13 & 19 & 30 \\
\hline $\mathrm{Rb}$ & 12 & 18,6 & 13,8 & 11,8 & 8,2 & 12,8 & 15,5 & 7 & 9,8 & 15,7 \\
\hline Cs & $*$ & 1 & * & 0,3 & * & $*$ & 0,6 & 0,2 & 0,2 & 0,1 \\
\hline $\mathrm{Sr}$ & 155,1 & 322,8 & 263,9 & 218,1 & 202 & 249,3 & 158,9 & 155,8 & 173,9 & 163,0 \\
\hline $\mathrm{Ba}$ & 71 & 77 & 121 & 68 & 82 & 107 & 71 & 80 & 74 & 105 \\
\hline Y & 24,4 & 30,1 & 22,7 & 22,8 & 22,4 & 20,8 & 24,4 & 19,4 & 20,4 & 25,4 \\
\hline $\mathrm{Zr}$ & 75,7 & 158,5 & 109,4 & 98,3 & 93,3 & 96,4 & 80,8 & 90 & 71,2 & 77,4 \\
\hline $\mathrm{Hf}$ & 2,5 & 3,7 & 3 & 2,5 & 2,6 & 2,4 & 2,6 & 2,2 & 2,0 & 2,5 \\
\hline $\mathrm{Nb}$ & 5,3 & 6,4 & 10,4 & 6,4 & 6,1 & 10 & 5,1 & 7,6 & 4,1 & 5,4 \\
\hline Ta & 0,3 & 0,4 & 0,6 & 0,4 & 0,4 & 0,6 & 0,4 & 0,4 & 0,3 & 0,4 \\
\hline $\mathrm{Pb}$ & 0,5 & 2,2 & 0,5 & 0,6 & 0,5 & 1,3 & 0,7 & 9,8 & 0,9 & 0,9 \\
\hline Th & 1,1 & 0,9 & 2,2 & 1,1 & 1,3 & 2,1 & 1,3 & 2,3 & 0,9 & 1,2 \\
\hline$U$ & 0,5 & 0,3 & 0,6 & 0,2 & 0,4 & 0,5 & 0,3 & 0,6 & 0,4 & 0,3 \\
\hline Ga & 17,7 & 15,9 & 16,4 & 17,1 & 16,5 & 15,4 & 17,6 & 15,3 & 16,7 & 16,9 \\
\hline $\mathrm{La}$ & 7,5 & 9,4 & 13,1 & 8,2 & 9,2 & 12,1 & 6,8 & 12,5 & 5,9 & 7,7 \\
\hline $\mathrm{Ce}$ & 16,8 & 23,7 & 29,5 & 19,4 & 21,1 & 27,4 & 16,7 & 24,2 & 14,4 & 17,3 \\
\hline $\operatorname{Pr}$ & 2,35 & 3,34 & 3,84 & 2,7 & 2,82 & 3,41 & 2,29 & 3,12 & 1,95 & 2,48 \\
\hline $\mathrm{Nd}$ & 11,8 & 16,2 & 16,2 & 12,9 & 11,9 & 15,8 & 10,3 & 13,7 & 9,4 & 11,7 \\
\hline $\mathrm{Sm}$ & 3,12 & 4,5 & 4,04 & 3,35 & 3,47 & 3,55 & 3,08 & 2,96 & 2,48 & 3,12 \\
\hline $\mathrm{Eu}$ & 1,18 & 1,57 & 1,35 & 1,2 & 1,19 & 1,18 & 1,14 & 0,89 & 0,98 & 1,15 \\
\hline $\mathrm{Gd}$ & 3,77 & 5,1 & 4,22 & 3,94 & 3,99 & 3,76 & 3,78 & 3,13 & 3,09 & 3,88 \\
\hline $\mathrm{Tb}$ & 0,71 & 0,88 & 0,74 & 0,71 & 0,72 & 0,67 & 0,7 & 0,56 & 0,58 & 0,71 \\
\hline Dy & 4,11 & 5,32 & 3,91 & 4,19 & 4,13 & 3,68 & 4,14 & 3,38 & 3,65 & 4,28 \\
\hline $\mathrm{Ho}$ & 0,9 & 1,05 & 0,86 & 0,87 & 0,87 & 0,77 & 0,86 & 0,74 & 0,71 & 0,91 \\
\hline $\mathrm{Er}$ & 2,67 & 3,19 & 2,57 & 2,42 & 2,62 & 2,07 & 2,56 & 2,18 & 2,18 & 2,65 \\
\hline $\mathrm{Tm}$ & 0,4 & 0,46 & 0,33 & 0,38 & 0,36 & 0,3 & 0,41 & 0,34 & 0,34 & 0,41 \\
\hline $\mathrm{Yb}$ & 2,36 & 2,66 & 2,01 & 2,11 & 2,16 & 1,98 & 2,62 & 2,31 & 2,02 & 2,42 \\
\hline $\mathrm{Lu}$ & 0,39 & 0,42 & 0,31 & 0,33 & 0,34 & 0,32 & 0,39 & 0,32 & 0,32 & 0,38 \\
\hline
\end{tabular}


Tabela 1. Continuação.

\begin{tabular}{|c|c|c|c|c|c|c|c|c|c|c|}
\hline Amostra & A11 & A12 & A13 & A14 & A15 & A16 & A17 & A18 & A19 & A20 \\
\hline $\mathrm{SiO}_{2}$ & 50,15 & 50,54 & 48,46 & 50,15 & 48,03 & 50,89 & 45,49 & 47,63 & 49,01 & 48,43 \\
\hline $\mathrm{TiO}_{2}$ & 1,14 & 1,32 & 1,06 & 1,38 & 1,46 & 1,51 & 1,16 & 1,54 & 1,60 & 1,66 \\
\hline $\mathrm{Al}_{2} \mathrm{O}_{3}$ & 14,56 & 13,83 & 15,95 & 14,39 & 15,66 & 14,39 & 16,52 & 15,25 & 15,03 & 20,76 \\
\hline $\mathrm{Fe}_{2} \mathrm{O}_{3}$ & 11,56 & 12,06 & 9,98 & 12,18 & 11,75 & 11,72 & 11,99 & 11,74 & 11,72 & 11,89 \\
\hline $\mathrm{MnO}$ & 0,19 & 0,19 & 0,17 & 0,19 & 0,18 & 0,19 & 0,17 & 0,17 & 0,17 & 0,17 \\
\hline MgO & 7,74 & 7,23 & 8,79 & 7,25 & 8,45 & 7,29 & 8,81 & 8,38 & 7,45 & 2,38 \\
\hline $\mathrm{CaO}$ & 11,03 & 10,68 & 11,52 & 10,56 & 10,58 & 10,28 & 11,91 & 10,88 & 10,74 & 6,04 \\
\hline $\mathrm{Na}_{2} \mathrm{O}$ & 2,3 & 2,22 & 2,31 & 2,22 & 2,14 & 1,95 & 1,15 & 2,09 & 2,30 & 5,25 \\
\hline $\mathrm{K}_{2} \mathrm{O}$ & 0,43 & 0,41 & 0,29 & 0,43 & 0,33 & 0,46 & 0,41 & 0,42 & 0,58 & 1,42 \\
\hline $\mathrm{P}_{2}^{2} \mathrm{O}_{5}$ & 0,1 & 0,11 & 0,04 & 0,13 & 0,12 & 0,12 & 0,09 & 0,13 & 0,16 & 0,4 \\
\hline LOI & 0,6 & 1,2 & 1,1 & 0,9 & 1 & 1 & 2 & 0,26 & 0,25 & 0,9 \\
\hline Total & 99,77 & 99,78 & 99,76 & 99,8 & 99,78 & 99,8 & 99,81 & 99,74 & 99,75 & 99,37 \\
\hline Sc & 42 & 40 & 35 & 39 & 34 & 40 & 38 & 33 & 33 & 25 \\
\hline V & 306 & 287 & 203 & 282 & 246 & 273 & 249 & 246 & 244 & 91 \\
\hline $\mathrm{Cr}$ & 116,32 & 109,47 & 355,79 & 102,63 & 307,90 & 198,42 & 561,05 & 362,63 & 294,21 & 54,74 \\
\hline Co & 43 & 42,4 & 39,6 & 41,5 & 46 & 45 & 46,5 & 47,7 & 45,1 & 20,1 \\
\hline $\mathrm{Ni}$ & 3,6 & 7,6 & 16 & 5,3 & 25,1 & 15,2 & 64,9 & 101 & 73 & 21 \\
\hline $\mathrm{Cu}$ & 0,9 & 28,6 & 22,2 & 8,8 & 77 & 31,2 & 130,1 & 75,8 & 58,9 & 25,7 \\
\hline $\mathrm{Zn}$ & 11 & 17 & 11 & 23 & 13 & 24 & 10 & 25 & 23 & 109 \\
\hline $\mathrm{Rb}$ & 13,6 & 14,9 & 7,6 & 16,1 & 8,6 & 16,5 & 8 & 13,0 & 20,7 & 58,4 \\
\hline Cs & 0,2 & 0,4 & 0,8 & 0,1 & 0,1 & * & 0,5 & 0,5 & * & 0,8 \\
\hline $\mathrm{Sr}$ & 175,1 & 162,6 & 194,4 & 161,4 & 211,6 & 187,6 & 231,7 & 226,8 & 248,2 & 1766,7 \\
\hline $\mathrm{Ba}$ & 81 & 82 & 56 & 101 & 138 & 107 & 67 & 110 & 170 & 1327 \\
\hline Y & 23,6 & 27,9 & 16,3 & 27,4 & 23,1 & 29,1 & 15,7 & 19,5 & 24,6 & 132,4 \\
\hline $\mathrm{Zr}$ & 69,7 & 84,4 & 60,5 & 88,4 & 102,3 & 100,4 & 54,5 & 107,6 & 130,5 & 866,5 \\
\hline $\mathrm{Hf}$ & 2,1 & 2,4 & 1,6 & 2,7 & 2,6 & 2,4 & 1,6 & 3,0 & 3,0 & 22,6 \\
\hline $\mathrm{Nb}$ & 4,6 & 5,1 & 4,2 & 5,7 & 6,1 & 5,7 & 10,9 & 10,9 & 11,9 & 35,7 \\
\hline $\mathrm{Ta}$ & 0,3 & 0,3 & 0,2 & 0,4 & 0,4 & 0,4 & 0,7 & 0,7 & 0,7 & 2,1 \\
\hline $\mathrm{Pb}$ & 0,4 & 1 & 1,5 & 0,7 & 0,6 & 1,1 & 5,1 & 3,2 & 1,3 & 5,4 \\
\hline Th & 1,2 & 1,3 & 0,9 & 1,2 & 1,3 & 2,1 & 1,6 & 1,7 & 2,5 & 44,5 \\
\hline U & 0,4 & 0,3 & 0,2 & 1,6 & 0,3 & 0,5 & 0,5 & 0,7 & 0,5 & 2,4 \\
\hline $\mathrm{Ga}$ & 17,9 & 17,4 & 14,5 & 17,9 & 16,2 & 15,8 & 17,6 & 17,1 & 16,9 & 28,9 \\
\hline La & 7,3 & 9,6 & 5,6 & 7,8 & 8,8 & 10,4 & 9,2 & 12,1 & 16,4 & 161,8 \\
\hline $\mathrm{Ce}$ & 15,3 & 22,2 & 13,3 & 16 & 18,1 & 24,6 & 19,4 & 28,4 & 32,9 & 324,2 \\
\hline $\operatorname{Pr}$ & 2,29 & 2,97 & 1,89 & 2,47 & 2,7 & 3,12 & 2,52 & 3,57 & 4,42 & 37 \\
\hline $\mathrm{Nd}$ & 10,2 & 13,7 & 9 & 12 & 13,7 & 14,8 & 11,8 & 16,4 & 20,7 & 147,4 \\
\hline Sm & 2,92 & 3,85 & 2,45 & 3,3 & 3,26 & 3,86 & 2,68 & 3,79 & 4,64 & 26,41 \\
\hline $\mathrm{Eu}$ & 1,19 & 1,23 & 1,01 & 1,21 & 1,17 & 1,41 & 1 & 1,27 & 1,43 & 3,18 \\
\hline $\mathrm{Gd}$ & 3,85 & 4,68 & 3,19 & 4,08 & 3,99 & 4,6 & 2,83 & 4,28 & 5,17 & 23,94 \\
\hline $\mathrm{Tb}$ & 0,68 & 0,8 & 0,48 & 0,78 & 0,71 & 0,85 & 0,49 & 0,68 & 0,79 & 3,96 \\
\hline Dy & 4,09 & 4,78 & 3,53 & 4,66 & 4,11 & 5,28 & 2,9 & 4,08 & 5,05 & 24,3 \\
\hline $\mathrm{Ho}$ & 0,87 & 1,03 & 0,62 & 1,02 & 0,88 & 1,12 & 0,59 & 0,78 & 0,94 & 5,09 \\
\hline Er & 2,51 & 2,85 & 1,7 & 2,83 & 2,41 & 3,33 & 1,77 & 2,20 & 2,83 & 14,13 \\
\hline $\mathrm{Tm}$ & 0,4 & 0,44 & 0,26 & 0,45 & 0,36 & 0,48 & 0,24 & 0,30 & 0,39 & 2,1 \\
\hline $\mathrm{Yb}$ & 2,61 & 2,85 & 1,63 & 2,7 & 2,24 & 2,73 & 1,55 & 2,10 & 2,42 & 11,6 \\
\hline Lu & 0,37 & 0,41 & 0,23 & 0,44 & 0,36 & 0,42 & 0,24 & 0,26 & 0,37 & 1,73 \\
\hline
\end{tabular}

*Valores abaixo do limite de detecção.

LOI: perda ao fogo. 
manchas irregulares ou pequenas lentes intersticiais ao anfibólio, definindo, em alguns casos, um bandamento composicional paralelo à foliação. Os cristais de plagioclásio são submilimétricos (com dimensões médias de $300 \mu \mathrm{m}$ ) e xenomórficos. Apresentam contatos lobulados a irregulares e, localmente, apresentam extinção ondulante e geminação lamelar (tipo albita) bem desenvolvida a ausente.

O quartzo (5-15\%) ocorre sob a forma de cristais com dimensões médias de $500 \mu \mathrm{m}$, xenomórficos, dispersos entre os cristais de plagioclásio, como inclusões arredondadas em plagioclásio e anfibólio e formando concentrações difusas (manchas irregulares), trilhas ou leitos descontínuos que ocorrem intersticialmente ao anfibólio. Os cristais normalmente apresentam extinção ondulante moderada a forte acompanhada de recuperação com subgrãos bem definidos e relativamente grandes com contatos lobulados, engrenados e localmente poligonais.

O epidoto/clinozoisita $(<4 \%)$ é xenomórfico a hipidiomórfico, submilimétrico (possui dimensões médias de $300 \mu \mathrm{m}$ ), ocorre disposto caoticamente (sem orientação) ou parcialmente orientado paralelamente à foliação. Quando produto de alteração do plagioclásio, apresenta dimensões menores e formas hipidiomórficas a xenomórficas ou massas irregulares amorfas. Quando desenvolvido intersticialmente ou alterando os anfibólios, apresenta dimensões maiores e é xenomórfico a hipidiomórfico.

A titanita é mineral acessório frequente, podendo, em alguns casos, perfazer cerca de $4 \%$ da lâmina. É xenomórfica a hipidiomórfica e ocorre dispersa, localmente marcando trilhas e/ou agregados lenticulares paralelos à foliação, ou envolvendo rutilo e/ou minerais opacos. As dimensões de seus cristais nunca ultrapassam $3 \mu \mathrm{m}$. Em alguns locais, a titanita ocorre com presença de minerais opacos (ilmenita) nas bordas.

A granada, quando ocorre, nunca ultrapassa os $2 \%$. É idiomórfica a hipidiomórfica e apresenta dimensões milimétricas ( $<200 \mu \mathrm{m}$ de diâmetro). Ocorre em agregados granulares, lenticulares, associada a quartzo e plagioclásio ou dispersa pela lâmina. Localmente, exibe bordas com alteração para biotita.

Os minerais opacos (magnetita/hematita/ilmenita) constituem até $3 \%$ da composição modal da lâmina. Ocorrem dispersos entre os cristais de anfibólio, como inclusões no anfibólio e na borda de cristais de rutilo e titanita. São xenomórficos com dimensões inferiores a $300 \mu \mathrm{m}$. Localmente, constituem trilhas descontínuas paralelas à foliação.

A biotita $(<1 \%)$ constitui palhetas submilimétricas $(<300 \mu \mathrm{m})$ tabulares a irregulares, de cor marrom amarelada, sendo normalmente não orientada e com pleocroísmo forte (amarelo acastanhado pálido em $\alpha$ e marrom escuro em $\gamma$ ). Em alguns locais, mostra textura de equilíbrio com o anfibólio; em outros, forma-se a partir desse mineral.
O rutilo $(<1 \%)$ ocorre como grãos irregulares, com dimensões inferiores a $100 \mu \mathrm{m}$. Ocorre disperso pela lâmina ou em agregados lenticulares descontínuos ou irregulares, normalmente com bordas de titanita e/ou ilmenita e/ou leucoxênio.

Localmente, ocorre clorita $(<1 \%)$ e esta aparece substituindo parcialmente os outros minerais (como anfibólio, biotita e granada). Forma palhetas com dimensões inferiores a $100 \mu \mathrm{m}$ não orientadas segundo a foliação principal, às vezes formando pequenos agregados irregulares. Possui cor verde pálida a quase incolor.

A apatita e a allanita ocorrem dispersas pela rocha e nunca ultrapassam $1 \%$ da composição modal da lâmina, com dimensões menores que $200 \mu \mathrm{m}$ e formas xenomórficas a idiomórficas.

Nas rochas metamáficas, as assembleias minerais relacionadas ao metamorfismo são representadas pelas associações: anfibólio + plagioclásio + (quartzo) + (rutilo) + (ilmenita), (granada) + anfibólio + plagioclásio + quartzo + (rutilo) + (ilmenita). Epidoto também ocorre associado em algumas amostras. Essas associações indicam que o metamorfismo atingiu condições de fácies anfibolito médio a superior (campo de estabilidade da cianita).

\section{GEOQUÍMICA DAS ROCHAS METAMÁFICAS}

Como as rochas metamáficas estudadas foram submetidas a processos tectonometamórficos (fácies anfibolito médio e xisto verde), utilizaram-se os diagramas $\mathrm{Na}_{2} \mathrm{O}$ versus $\mathrm{CaO}$ (Vallance, 1974) e $\mathrm{Na}_{2} \mathrm{O}+\mathrm{K}_{2} \mathrm{O}$ versus $\mathrm{Na}_{2} \mathrm{O} / \mathrm{K}_{2} \mathrm{O}$ (Miyashiro, 1975) para avaliar possíveis mudanças químicas na composição original dos protólitos das rochas analisadas (Figura 4). Esses diagramas sugerem que uma amostra (amostra A20, Tabela 1) pode ter sofrido modificação química significativa, principalmente em relação a $\mathrm{Na}_{2} \mathrm{O}, \mathrm{K}_{2} \mathrm{O}$ e $\mathrm{CaO}$.

Devido à ausência de estruturas, mineralogia ou texturas primárias, em função da deformação e recristalização ocorrida durante a evolução tectono-metamórfica das rochas estudadas, a natureza do protólito (orto- ou para-derivado) dessas rochas foi caracterizada utilizando-se o diagrama de Leake (1964), que utiliza os parâmetros e/ou números de Niggli (1954) (Figura 5).

A amostra com indício de modificação química (Figura 4, amostra A20) e que plota fora do trend de rochas de origem ígnea (Figura 5, amostra A20) foi excluída das discussões subsequentes, embora, em alguns casos, mesmo quando há evidências de modificações químicas significativas de elementos móveis, como álcalis, nem sempre os elementos menos móveis (como elementos terras raras pesadas - ETRP, Y, HFSE etc.) mostram perdas ou ganhos significativos com a alteração e/ou metamorfismo. 
A

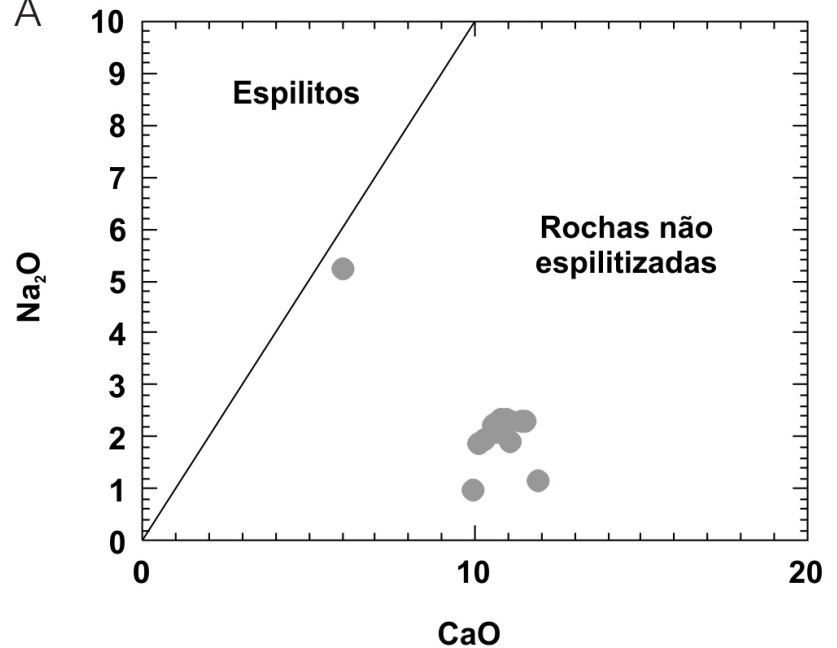

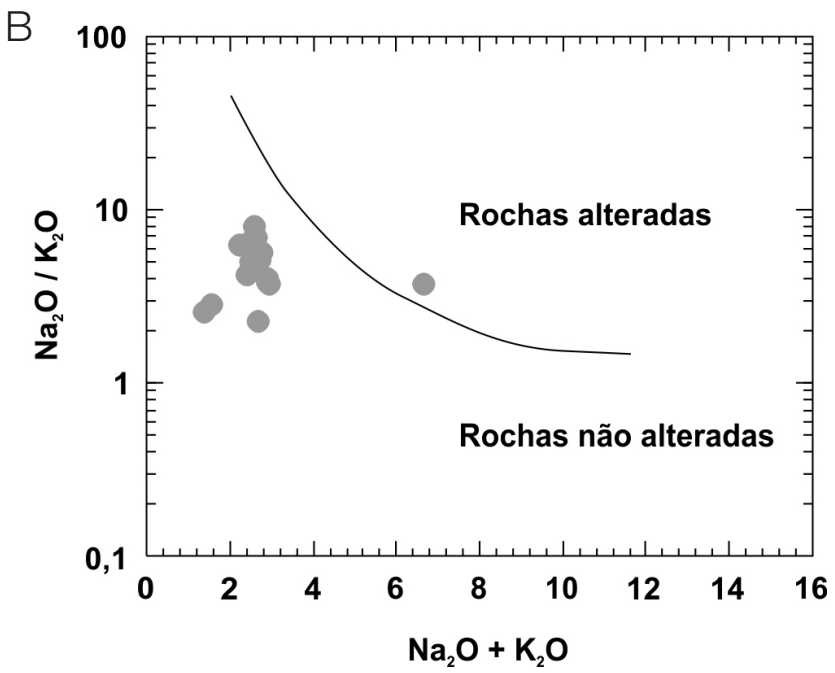

Figura 4. (A) Diagrama discriminante para rochas espilitizadas e não espilitizadas (Vallance, 1974); (B) diagrama de Miyashiro (1975) para discriminação de rochas que sofreram modificações químicas por processos pós-magmáticos.

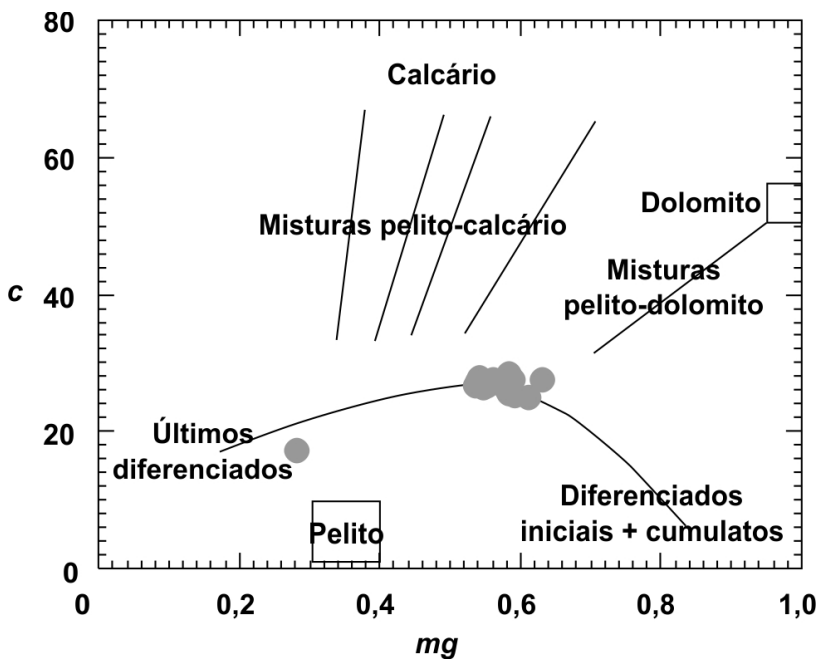

mg e c: parâmetros de Niggli (1954).

Figura 5. Diagrama (Leake, 1964) para caracterização química da origem dos protólitos de rochas metamáficas.

Quimicamente, as amostras apresentam natureza básica $\left(\mathrm{SiO}_{2}=45,49-50,89 \%\right)$, predominando composições de basaltos subalcalinos e de basaltos andesíticos (Figura 6) e apresentam afinidade toleítica subalcalina (Figura 7).

O conjunto de amostras analisadas não apresenta trends bem definidos, com pequena variação nos conteúdos de $\mathrm{Al}_{2} \mathrm{O}_{3}$ $(13,83-16,98 \%), \mathrm{Fe}_{2} \mathrm{O}_{3} \mathrm{~T}(9,98-12,18 \%), \mathrm{MnO}(0,16-$ $0,19 \%), \mathrm{CaO}(9,95-11,91 \%)$ e de $\mathrm{MgO}(7,23-8,81 \%)$ (Figura 8). Os valores de $\mathrm{Na}_{2} \mathrm{O}$ variam entre 0,98 e 2,35\%, de $\mathrm{K}_{2} \mathrm{O}$ entre 0,29 e $0,82 \%$, de $\mathrm{TiO}_{2}$ entre 1,06 e $1,81 \%$ e de $\mathrm{P}_{2} \mathrm{O}_{5}$ entre 0,04 e $0,17 \%$. Os elementos traço (Tabela 1 , Figura 8), analisados em diagramas versus $\mathrm{MgO}$, apresentam pequena variação, assim como foi observado nos elementos maiores. Apresentam teores de Cs variando entre 0,1 e 1 ppm, de Rb entre 7 e 20,7 ppm, de Hf entre 1,6 e 3,7 ppm, de Th entre 0,9 e 2,5 ppm, de U entre 0,2 e 1,6 ppm e de Ta entre 0,2 e 0,7 ppm. Apresentam teores de Y de 15,7 a 30,1 ppm, de Ba de 81 a 170 ppm, de Sr de 155,1 a 322,8 ppm, de Pb de 0,4 a 9,8 ppm, de $\mathrm{Nb}$ de 4,1 a 11,9 ppm, de $\mathrm{Zr}$ de 54,5 a 158,5 ppm, de Ni de 3,6 a 101 ppm e de Cr de 102,63 a 561,05 ppm. Os conteúdos de V, Sc e Ga variam entre 203 e 309 ppm, 32 e 42 ppm e 14,5 e 17,9 ppm, respectivamente. Nos diagramas binários de elementos traço versus $\mathrm{MgO}$, não se observam trends ou grupos bem definidos. O MgO exibe fraca correlação negativa em relação a $\mathrm{SiO}_{2}, \mathrm{Y}, \mathrm{V}, \mathrm{Ga}$ e positiva com relação a $\mathrm{Al}_{2} \mathrm{O}_{3}, \mathrm{~Pb}, \mathrm{Ni}$ e $\mathrm{Cr}$ (Figura 8).

O conteúdo total de ETR é baixo $\left(\Sigma \mathrm{ETR}_{\text {Total }}=44,89\right.$ a 98,45 ppm), em geral com teores menores que 90 ppm (Tabela 1), com predomínio de ETRL sobre ETRP $\left(\Sigma \mathrm{ETRL}_{\text {Total }}=33,25\right.$ a $80,49 \mathrm{ppm}, \Sigma \mathrm{ETRP}_{\text {Total }}=10,61 \mathrm{a}$ $19,08 \mathrm{ppm})$, apresentando fraco fracionamento $\left(\mathrm{La}_{\mathrm{N}} / \mathrm{Lu}_{\mathrm{N}}=\right.$ 1,81 a 4,83). Os ETRL normalizados pelo condrito (Taylor e MacLennan, 1985) apresentam concentrações entre 10,23 e 44,69 vezes acima do condrito, enquanto que os ETRP, entre 6,04 e 16,90 vezes (Figura 9A). Os ETRL apresentam pouca inclinação, evidenciando fraco enriquecimento $\left(\mathrm{La}_{\mathrm{N}} / \mathrm{Eu}_{\mathrm{N}}=\right.$ 1,31 a 3,33), enquanto que os ETRP tendem a sub-horizontal, mostrando também fraco enriquecimento $\left(\mathrm{Gd}_{\mathrm{N}} / \mathrm{Lu}_{\mathrm{N}}=1,15\right.$ a 2,05). Discretas anomalias negativas $\left(\mathrm{Eu}^{*}=0,88\right.$ a 0,9$)$ são observadas em algumas amostras, sugerindo o fracionamento de plagioclásio ou anfibólio durante a cristalização do protólito. O padrão de distribuição de ETR das amostras analisadas é semelhante ao padrão de distribuição de ETR para basaltos tipo E-MORB (basaltos enriquecidos de cadeia meso oceânica) e IABT (basaltos toleíticos de arco de ilha). 

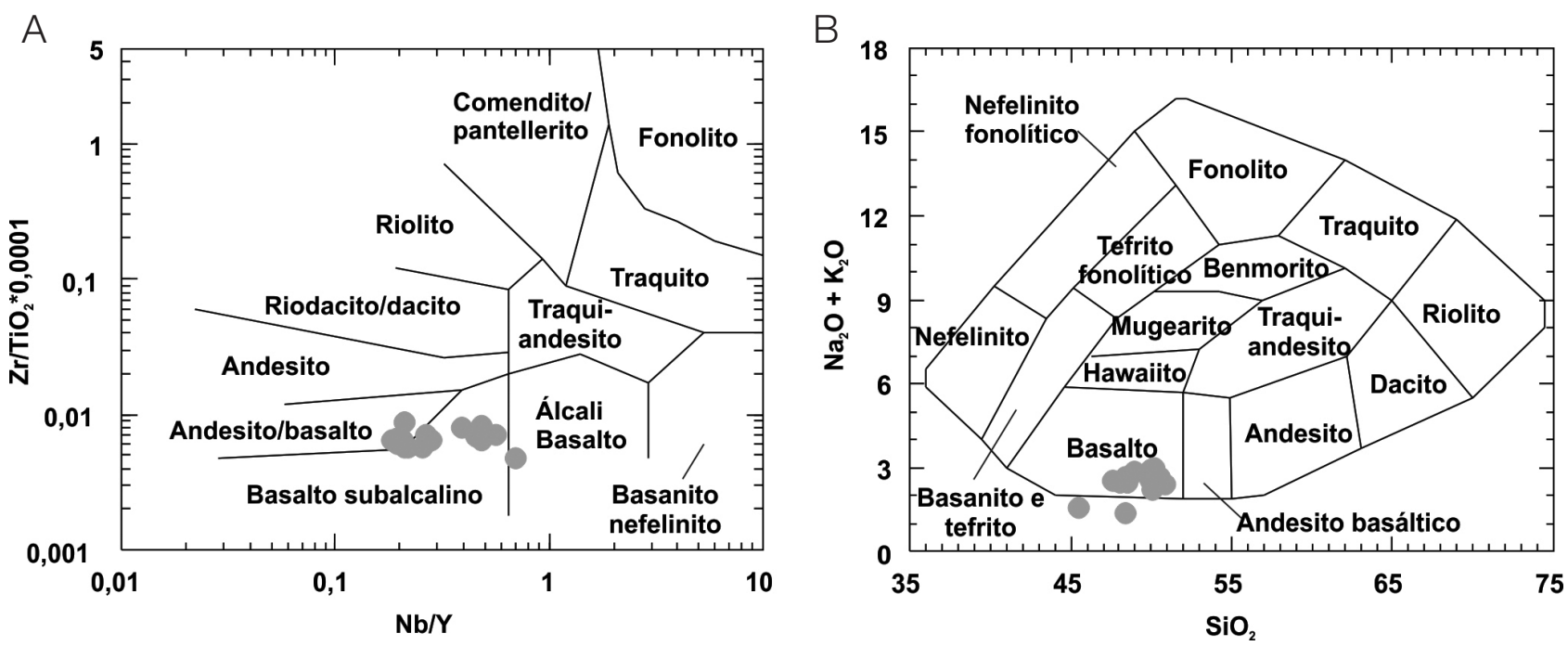

Figura 6. Diagramas de classificação composicional das amostras de rochas metamáficas da área de estudo. (A) Diagrama de Winchester e Floyd (1977); (B) diagrama de Cox et al. (1979).
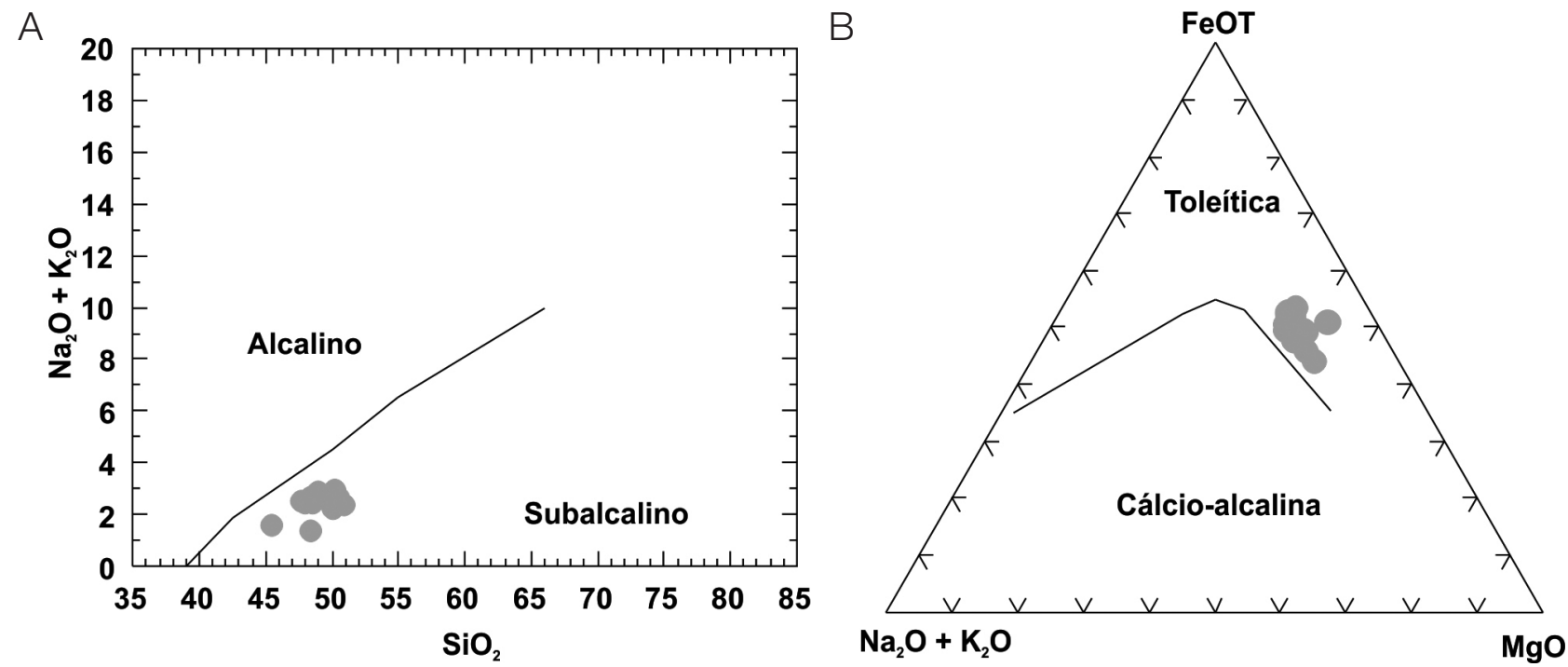

Figura 7. (A) Diagrama de álcalis versus sílica (Irvine e Baragar, 1971) ilustrando a natureza subalcalina das amostras; (B) diagrama AFM (Irvine e Baragar, 1971, $\mathrm{A}=\mathrm{Na}_{2} \mathrm{O}+\mathrm{K}_{2} \mathrm{O} ; \mathrm{F}=\mathrm{FeO}_{\mathrm{T}}, \mathrm{M}=\mathrm{MgO}$ ) mostrando o caráter toleítico das amostras analisadas.

A distribuição dos elementos traço normalizados pelos valores de N-MORB (basaltos normais de cadeia meso-oceânica, Sun e McDonough, 1989) mostra que as rochas analisadas apresentam enriquecimento em $\mathrm{Cs}, \mathrm{Rb}, \mathrm{Ba}, \mathrm{K}$, Th e U em relação a Nb, Ta, ETR, Sr, P, Zr, Hf, Ti e Y, mostrando fracas a médias anomalias negativas de Nb, Ta e P (Figura 9B).

Nos diagramas binários $\mathrm{TiO}_{2} / \mathrm{Yb}-\mathrm{Nb} / \mathrm{Yb}$ e $\mathrm{Zr} / \mathrm{Yb}-\mathrm{Nb} /$ $\mathrm{Yb}$ (Pearce e Peate, 1995) (Figuras 10A e 10B), as amostras analisadas mostram composição de basaltos tipo MORB em relação a esses elementos, e nos diagramas $\mathrm{Th} / \mathrm{Yb}-\mathrm{Nb} / \mathrm{Yb}$ (Pearce e Peate, 1995) e Th/Yb-Ta/Yb (Pearce, 1983), as amostras sugerem uma composição de basaltos gerados em ambiente de arco de ilha (Figuras 10C e 10D). Nos diagramas discriminantes Hf/3-Th-Ta, Hf/3-Th-Nb/16 (Wood, 1980) e $\mathrm{Nb} * 2-\mathrm{Zr} / 4-\mathrm{Y}$ (Meschede, 1986), as amostras de metamáficas analisadas exibem composição química semelhante a basaltos tipo MORB e a basaltos de arcos de ilha, também sugerindo que essas rochas tiveram origem em zona de subdução, em arco de ilha pouco evoluído (Figura 11). O enriquecimento em LILE em relação a HFSE e ETR, mostrando anomalias negativas de $\mathrm{Nb}$, Ta e $\mathrm{P}$, também sugere que essas rochas tiveram como contribuição fontes geradas em arcos vulcânicos. 

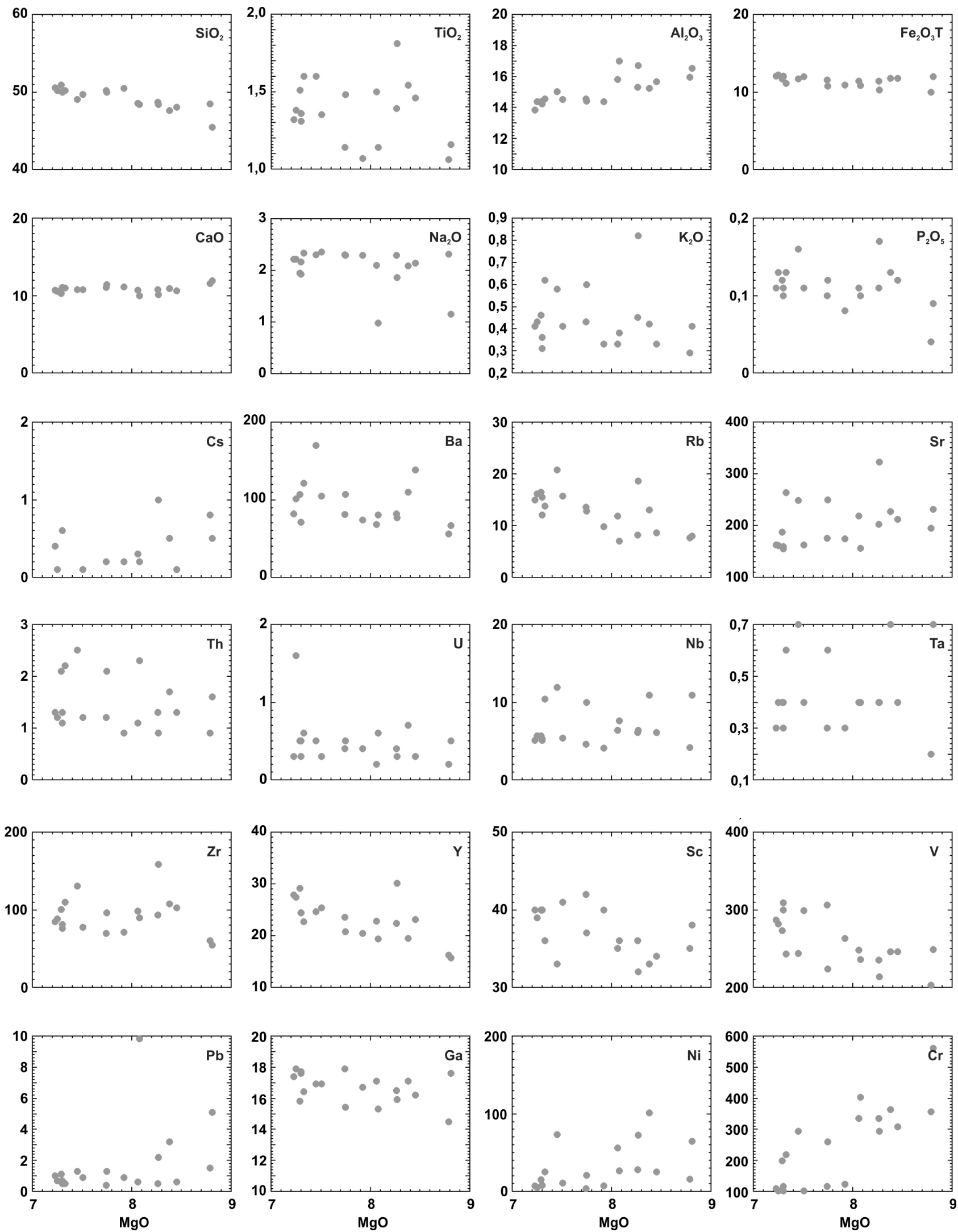

Figura 8. Diagramas binários de elementos maiores $\left(\mathrm{SiO}_{2}, \mathrm{TiO}_{2}, \mathrm{Al}_{2} \mathrm{O}_{3}, \mathrm{Fe}_{2} \mathrm{O}_{3} \mathrm{~T}, \mathrm{CaO}, \mathrm{Na}_{2} \mathrm{O} \mathrm{K}_{2} \mathrm{O}\right.$ e $\left.\mathrm{P}_{2} \mathrm{O}_{5}\right)$ e traços $(\mathrm{Cs}$, Ba, $\mathrm{Rb}, \mathrm{Sr}$, Th, U, Nb, Ta, Zr, Y, Sc, V, Pb, Ga, Ni, Cr) versus MgO, mostrando a variação da composição das amostras. 

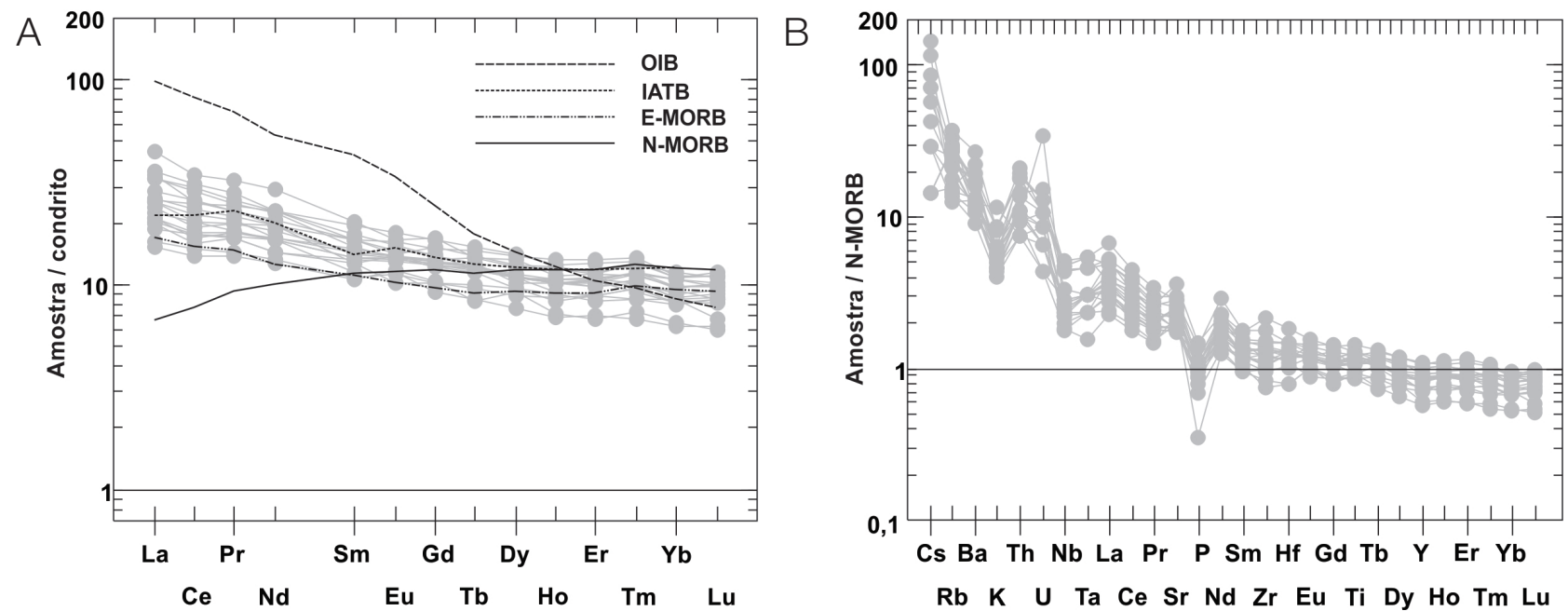

OIB: basalto de ilha oceânica; IATB: basalto toleítico de arco de ilha; E-MORB: basalto enriquecido de cadeia meso-oceânica; N-MORB: basalto normal de cadeia meso-oceânica. Valores compilados de: Taylor e MacLennan (1985); Sun e McDonough (1989); Wilson (1989).

Figura 9. (A) Diagramas de elementos terras raras (ETR) das rochas metamáficas analisadas e de basaltos de outros ambientes tectônicos normalizados pelo condrito; (B) padrões de distribuição de elementos traços e ETR normalizados pelos valores de N-MORB (Sun e McDonough, 1989) para as amostras de metamáficas analisadas.

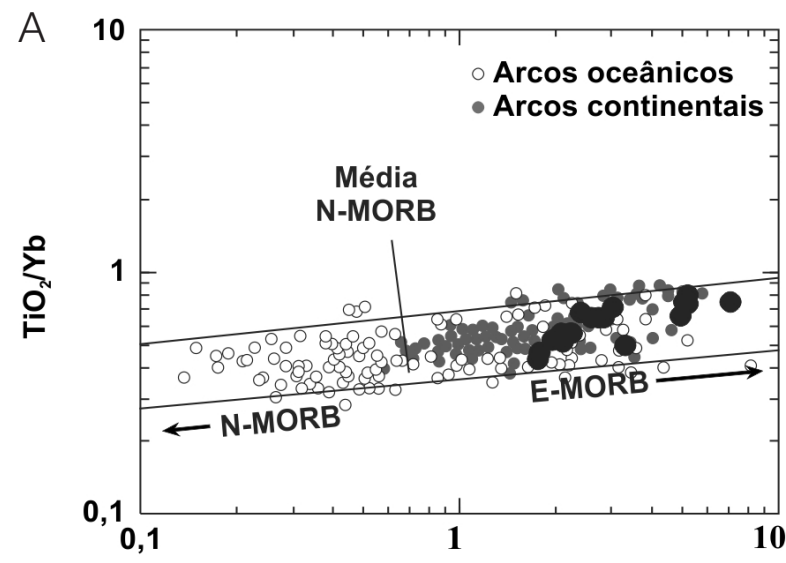

B
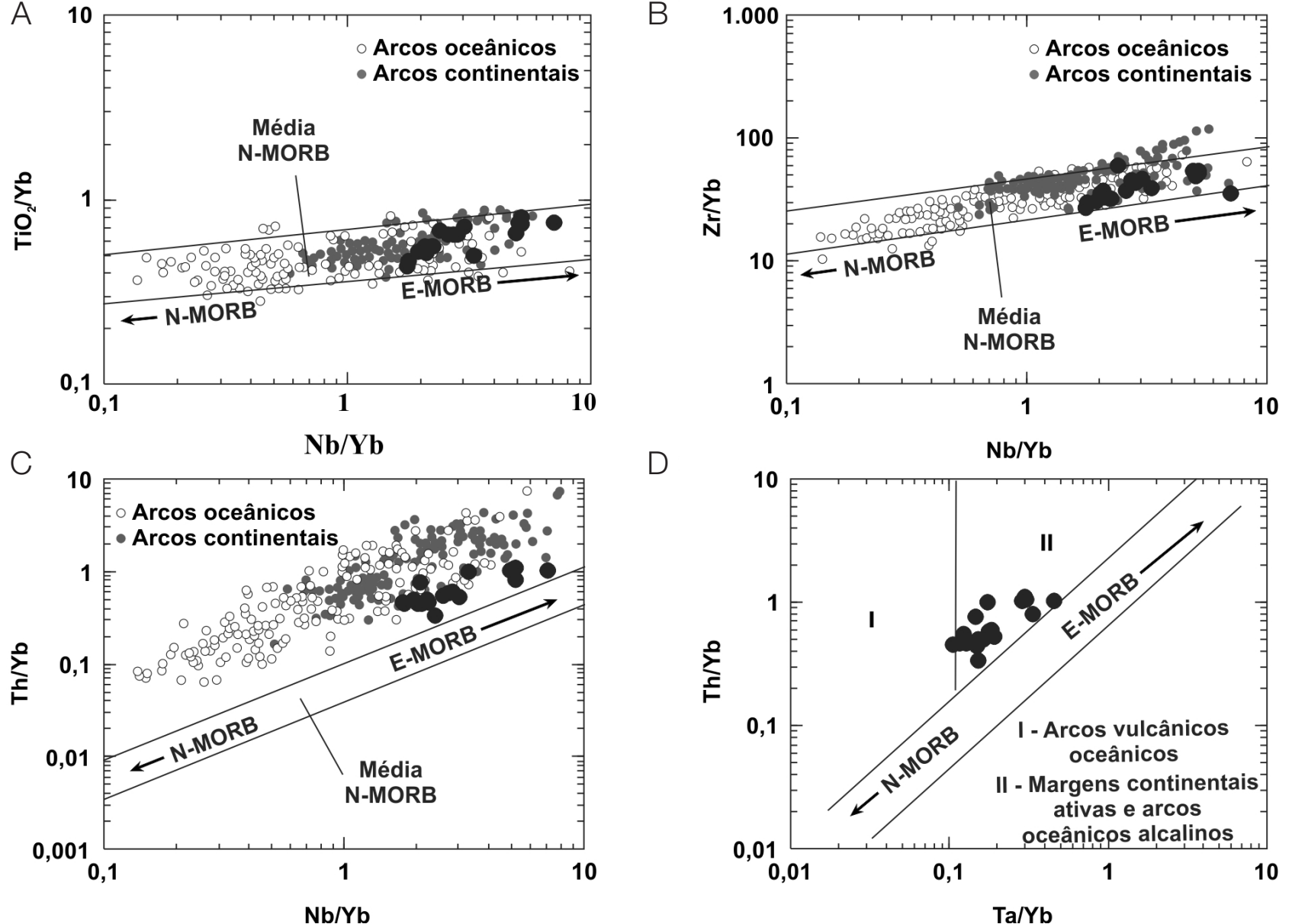

N-MORB: basalto normal de cadeia meso-oceânica; E-MORB: basalto enriquecido de cadeia meso-oceânica. Círculos brancos e cinza escuros: dados de Pearce e Peate (1995).

Figura 10. Diagramas discriminantes indicativos de ambientes de geração de magmas básicos. (A) $\mathrm{TiO}_{2} / \mathrm{Yb}-\mathrm{Nb} / \mathrm{Yb}$; (B) Zr/Yb-Nb/Yb; (C) Th/Yb-Nb/Yb (Pearce e Peate, 1995); (D) Th/Yb-Ta/Yb (Pearce, 1983). 


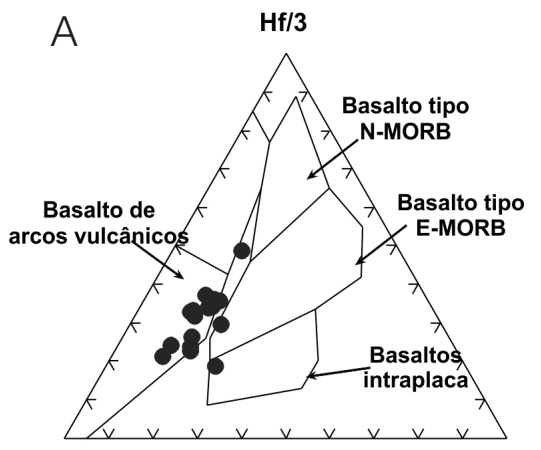

Th

Ta Th
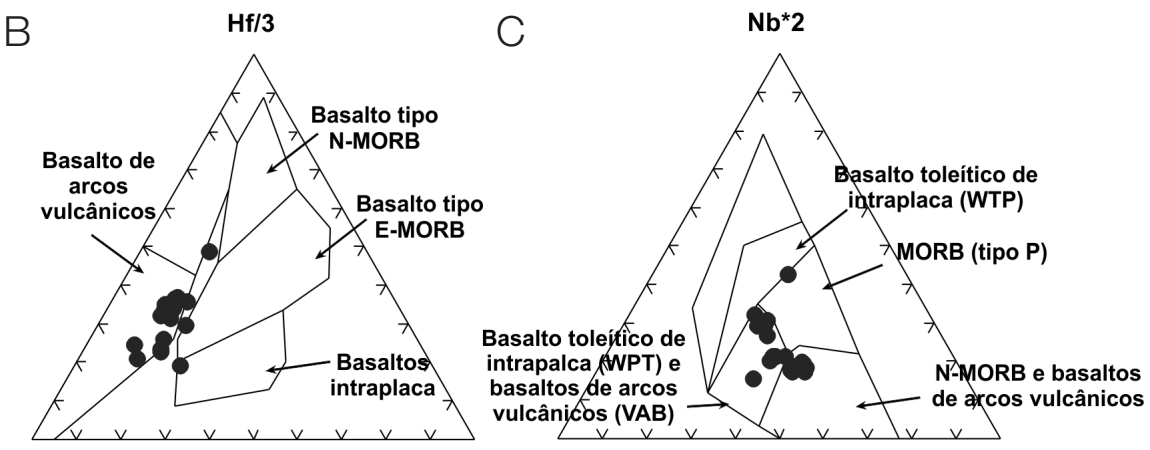

$\mathrm{Nb} / 16 \quad \mathrm{Zr} / 4$

MORB: basalto de cadeia meso-oceânica; N-MORB: basalto normal de cadeia meso-oceânica; E-MORB: basalto enriquecido de cadeia meso-oceânica.

Figura 11. Diagramas discriminantes de ambientes tectônicos. (A) Hf/3-Th-Ta; (B) Hf/3-Th-Nb/16 (Wood, 1980); (C) Nb*2Zr/4-Y (Meschede, 1986).

\section{CONCLUSÕES}

Os padrões químicos de ETR, elementos maiores e elementos traços observados nas amostras analisadas não mostram variação significativa nos conteúdos, indicando que essas rochas podem ser provenientes de uma fonte com características químicas semelhantes. As amostras apresentam composições variando de basaltos subalcalinos a basaltos andesíticos com afinidade toleítica subalcalina. A distribuição dos elementos traço mostra um enriquecimento em LILE (Cs, Rb, Ba, K, Th e U) e ETRL em relação a $\operatorname{HFSE~(Nb,~}$ Ta, Zr, Hf e Y) e aos ETRP, Sr, P e Ti, mostrando fracas a médias anomalias negativas de $\mathrm{Nb}$, Ta e P. As amostras analisadas na região de Indiara (GO) possuem características geoquímicas semelhantes a rochas geradas em ambientes de arcos magmáticos.

\section{REFERÊNCIAS}

Almeida, F. F. M. (1967). Origem e evolução da Plataforma Brasileira. Rio de Janeiro: DNPM/DGM, 1967. Boletim 241.

Almeida, F. F. M., Hasui Y., Brito-Neves, B. B., Fuck, R. A. (1981). Brazilian Structural Provinces: an introduction. Earth-Science Reviews, 78(17), 1-29.

Araújo, V. A., Godoi, P. V. B., Araujo, H. O., Moreton, E. S., Silva, L. C., Sá, M. A. D., Martins, A. M., Matos, E. G., Andrade, S. H. S., Sales, R., Bebert, C. O., Olivatti, O. (1980). Projeto Pontalina - Fase I. Goiânia: SURGEO/GO, DNPM, CPRM. 7v.

Barbosa, O., Baptista, M. B., Dyer, R. C., Braun, O. P. G., Fratin, H., Meneguesso, G. (1970). Projeto Goiânia, Relatório preliminar. Rio de Janeiro: DNPM/PROSPEC.
Barbosa, O., Ramos, J. R. A., Gomes, F. A., Helmbold, R. (1966). Geologia estratigráfica, estrutural e econômica da área do "Projeto Araguaia”. Brasília: Ministério de Minas e Energia, Departamento Nacional da Produção Mineral, Divisão de Geologia e Mineralogia.

Barbosa, P. A. R. (1987). Geologia e recursos minerais das sequências supracrustais a leste de Mossâmedes-GO. Dissertação (Mestrado). Brasília: Instituto de Geociências - UnB.

Cox, K. G., Bell, J. D., Pankhurst, R. J. (1979). The interpretation of igneous rocks. London: Chapman \& Hall.

Danni, J. C. M., Fuck, R. A. (1981). Unidades tectonoestratigráficas do embasamento das faixas dobradas da margem ocidental do Cráton do São Francisco. II Simpósio Sobre o Cráton do São Francisco e suas Faixas Marginais, 130-139. Salvador: SBG.

Dardenne, M. A. (2000). The Brazilia Fold Belt. In: U. G. Cordani, E. J. Milani, A. Thomas Filho, D. A. Campos (Coords.), Tectonic evolution of South America (231-236), Rio de Janeiro: SBG.

De La Roche, H., Leterrier, J., Grandclaude, P., Marchal, M. (1980). A classification of volcanic and plutonic rocks using R1R2 - diagram and major-element analyses - ITS relationships with current nomenclature. Chemical Geology, 29, 183-210.

Fuck, R. A. (1990). Dobramentos neoproterozóicos da margem Ocidental do Cráton do São Francisco: revisão. XXXVI Congresso Brasileiro de Geologia, v. 1, 288-289. Natal: SBG.

Fuck, R. A. (1994). A Faixa Brasília e a compartimentação tectônica na Província Tocantins. IV Simpósio de Geologia do centro-oeste, 184-187. Brasília: SBG. 
Fuck, R. A., Pimentel, M. M., Silva, D. R., Luiz, J. H. (1994). Compartimentação tectônica na porção oriental da Província Tocantins. XXXVIII Congresso Brasileiro de Geologia, v. 1, 215-216. Camburiú: SBG.

Fuck, R. A., Pimentel, M. M., Soares, J. E. P., Dantas, E. L. (2005). Compartimentação da Faixa Brasília. IX Simpósio de Geologia do centro-oeste, 26-27. Goiânia: SBG.

Ianhez, A. C., Pitthan, J. H. L., Simões, M. A., Del' Arca, J. O., Trindade, C. A. H., Luz, D. S., Fernandes, C. A. C. (1983). Geologia. In: Projeto RADAM BRASIL: Folha SE. 22 Goiânia (v. 31, 23-348). Rio de Janeiro: MME-SG.

Irvine, T., Baragar, W. (1971). A guide to the chemical classification of the common volcanic rocks. Canadian Journal of Earth Sciences, 8(5), 523-548.

Lacerda Filho, J. V., Oliveira, C. C. (1994). Gênese e evolução geológica das rochas granitóides da região sul de Goiás. XXXVIII Congresso Brasileiro de Geologia, v. 1, 146-147. Camboriú: SBG.

Lacerda Filho, J. V., Rezende, A., Silva, A. (1999). Programa de levantamentos geológicos básicos do Brasil - Geologia e Recursos Minerais do Estado de Goiás e Distrito Federal (2a ed.). Goiânia: CPRM; METAGO; UnB.

Laux, J. H., Pimentel, M. M., Dantas, E. L. (2001). Preliminary $\mathrm{Nd}$ isotopic data for the Anicuns-Itaberaí Sequence, associated orthogneisses and granite instrusions, Goiás, Brazil. IV Simpósio Geologia Isotópica. Chile. (CD-ROM).

Laux, J. H., Pimentel, M. M., Dantas, E. L., Armstrong, R., Armele, A. (2003). New U-Pb data for ortogneisses oh the neoproterozoic Goiás Magmatic Arc, central Brazil. IV South American Symposium on Isotopic Geology, 579-582. Salvador: SBG.

Laux, J. H., Pimentel, M. M., Dantas, E. L., Armstrong, R., Junges, S. L. (2005). Two Neoproterozoic crustal accretion events in the Brasília Belt, central Brazil. Journal of South American Earth Sciences, 18(1), 183-198.

Laux, J. H., Pimentel, M. M., Gioia, S. M. C. L., Ferreira, V. P. (2010). The Anicuns-Itaberaí volcano-sedimentary sequence, Goiás Magmatic Arc: new geochemical and Nd-S isotopic data. Geochimica Brasiliensis, 24(1), 13-28.

Leake, B. E. (1964). The chemical distinction between orthoand para-amphibolites. Journal of Petrology, 5(2), 238-254.
Maniar, P. D., Picolli, P. M. (1989). Tectonic discriminant of granitoids. Geological Society of American Bulletin, 101, 635-643.

Marini, O. J., Fuck, R. A., Danni, J. C. M., Dardene, M. A., Lougguércio, R. O., Ramalho, R. (1984a). As faixas de dobramentos Brasília, Uruaçu e Paraguai-Araguaia e o Maciço Mediano de Goiás. In: C. Schobbenhaus, D. A. Campos, G. R. Derze, H. E. Asmus. (Coords.), Geologia do Brasil (251-303). Brasília: DNPM.

Marini, O. J., Fuck, R. A., Dardene, M. A., Danni, J. C. M. (1984b). Província Tocantins: setores Central e Sudeste. In: F. F. M. Almeida, Y. Hasuy (Coords.), O Pré-cambriano do Brasil (205-264). São Paulo: Edgar Blücher.

Marini, O. J., Fuck, R. A., Dardene, M. A., Teixeira, N. A. (1978). Dobramentos da borda oeste do Cráton do São Francisco. I Simpósio Sobre o Cráton do São Francisco e suas Faixas Marginais, v. 3, 155-204. Salvador: SBG.

Meschede, M. (1986). A method of discriminating between different types of mid-ocean ridge basalts and continental tholeiites with the Nb-Zr-Y diagram. Chemical Geology, $56,207-218$.

Miyashiro, A. (1975). Classification, characteristics, and origin of ophiolites. Journal of Geology, 83, 249-281.

Moreira, M. L. O., Moreton, L. C., Araújo, V. A., Lacerda Filho, J. V., Costa, H. F. (2008). Geologia do Estado de Goiás e Distrito Federal. Brasília: MME; CPRM-SIC; FUNMINERAL/GO.

Navarro, G. R. B., Zanardo, A., Conceição, F. T., Montibeller, C. C. (2013a). Geoquímica e geocronologia U-Pb e Sm-Nd dos ortognaisses da região de Pontalina (GO), Brasil. Brazilian Journal of Geology, 43(2), 317-332.

Navarro, G. R. B., Zanardo, A., Conceição, F. T., Montibeller, C. C. (2013b). Geoquímica de gnaisses da região de Indiara-GO. XIV Congresso Brasileiro de Geoquímica. Diamantina: SBG. (CD-ROM).

Navarro, G. R. B., Zanardo, A., Galembeck, T. M. B., Rocha, M. M. C. (2004). Idades modelo dos gnaisses da região de Pontalina Goiás. LII Congresso Brasileiro de Geologia, Araxá: SBG. (CD-ROM).

Niggli, P. (1954). Rocks and mineral deposits. San Francisco: W. H. Freeman \& CO. 
Oliveira, C. C., Bittar, N. (1971). Geologia das Folhas de Itauçu, Palmeiras de Goiás e Cesarina e Cadastramento de Materiais de Construção da Área Goiânia-Trindade. Projeto Bandeirante. Goiânia: CPRM.

Pearce, J. A. (1983). Role of the sub-continental lithosphere in magma genesis at active continental margins. In: C. J. Hawkesworth, M. J. Norry (Eds.), Continental basalts and mantle xenoliths (230-249). Cambridge: Shiva Publishing Ltd..

Pearce, J. A., Harris, N. B. W., Tindle, A. G. (1984). Trace element discrimination diagrams for the tectonic interpretation of granitic rocks. Journal of Petrology, 25, 956-983.

Pearce, J. A., Peate, D. W. (1995). Tectonic implications of the composition of volcanic arc magmas. Annual Reviews Earth and Planetary Science, 23, 251-285.

Pimentel, M. M., Fuck, R. A. (1991). Origin of orthogneiss and metavolcanic rock units in western Goiás: Neoproterozoic crustal accretion. Geochimica Brasiliensis, 5(1/2), 133-152.

Pimentel, M. M., Fuck, R. A. (1992). Neoproterozoic crustal accretion in central Brazil. Geology, 20, 375-379.

Pimentel, M. M., Fuck, R. A., Gioia, S. M. C. L. (2000b). The Neoproterozoic Goiás Magmatic Arc, central Brazil: a review and new Sm-Nd isotopic data. Revista Brasileira de Geociências, 2(30), 35-39.

Pimentel, M. M., Fuck, R. A., Jost, H., Ferreira Filho, C. F., Araujo, S. M. (2000a). The basament of the Brasilia Fold Belt and the Goiás Magmatic Arc. In: U. G. Cordani, E. J. Milani, A. Thomas Filho, D. A. Campos (Coords.), Tectonic Evolution of South America (195-229). Rio de Janeiro: SBG.

Pimentel, M. M., Jost, H., Fuck, R. A. (2004). O embasamento da Faixa Brasília e o Arco Magmático de Goiás. In: V. Mantesso-Neto, A. Bartorelli, C. D. R. Carneiro, B. B. Brito-Neves (Orgs.), Geologia do continente sul-americano: evolução da obra de Fernando Flávio Marques de Almeida (355-368). São Paulo: Beca.

Richard, L. R. (1995). MINPET - Mineralogical and Petrogical Data Processing Sistem,version 2.02. Quebec: MinPet Geological Software.

Rodrigues, J. N. B., Gioia, S. M. L. C., Pimentel, M. M. (1999). Geocronologia e geoquímica de ortognaisses da região entre Iporá e Firminópolis: implicações para a evolução do Arco Magmático de Goiás. Brazilian Journal of Geology, 29(2), 207-216.
Schobbenhaus, F. C., Oguino, K., Ribeiro, C. L., Oliva, L. A., Takanohashi, J. T. (1975a). Carta Geológica do Brasil ao Milionésimo; Folha Goiânia (SE.22). Brasília: Departamento Nacional de Produção Mineral.

Schobbenhaus, F. C., Ribeiro, C. L., Oliva, L. A., Takanohashi, J. T., Lindenmayer, Z. G., Vasconcelos, J. B., Orlandi, V. (1975b). Carta Geológica do Brasil ao Milionésimo; Folha Goiás, (SD.22). Brasília: Departamento Nacional de Produção Mineral.

Simões, L. S. A. (2005). Compartimentos crustais do domínio interno da Faixa Brasília no Sul de Goiás. Tese (LivreDocência). Rio Claro: Instituto de Geociências e Ciências Exatas - UNESP.

Sun S. S., McDonough W. F. (1989). Chemical and isotopic systematics of oceanic basalts: implications for mantle composition and processes. In: Geological Society of London, Magmatismo in the ocean basins.Special Publication (n. 42, 313-345).

Taylor, S. R., Maclennan, S. M. (1985). The continental crust: its composition and evolution. Oxford: Blackwell.

Valente, C. R. (1986). Projeto Mapas Metalogenéticos e de Previssão de Recursos Minerais. Folha Morrinhos, SE.22$X$-D. Brasília: DNPM; CPRM; SRG.

Vallance, T. G. (1974). Spilitic degradation of a tholeiitic basalt. Journal Petrology, 15, 79-96.

Viana, M. G., Pimentel, M. M., Whitehouse, M. J., Fuck, R. A., Machado, N. (1995). O Arco Magmático de Mara Rosa, Goiás: geoquímica e geocronologia e suas implicações regionais. Revista Brasileira de Geociências, 25(2), 111-123.

Wilson, B. M. (1989). Igneous petrogenesis a global tectonic approach. New York: Springer.

Winchester, J. A., Floyd, P. A. (1977). Geochemical discrimination of different magma series and their differentiation products using immobile elements. Chemical Geology, 20, 325-343.

Wood, D. A. (1980). The application of Th-Hf-Ta diagram to problems of tectonomagmatic classification and to establishing the nature of crustal contamination of basaltic lavas of the British Tertiary Volcanic Province. Earth and Planetary Science Letters, 50(1), 11-30. 